\title{
Radionuclide and Colloid Transport in the Culebra Dolomite and Associated Complementary Cumulative Distribution Functions in the 1996 Performance Assessment for the Waste Isolation Pilot Plant
}

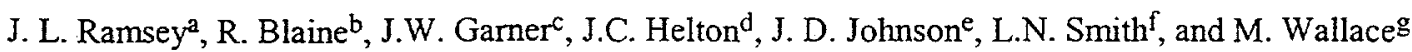 \\ Q $\leqq \frac{x}{\pi}$ \\ aSandia National Laboratories, Albuquerque, NM 87185 USA; bEcodynamics Research Associates, \\ Albuquerque, NM 87106 USA; 'Piru Associates, Albuquerque, NM 87106 USA; dDepartment of \\ Mathematics, Arizona State University, Tempe, AZ 85287 USA; ${ }^{e}$ GRAM, Inc., Albuquerque, NM 87112 \\ USA; fComforce, Albuquerque, NM 87110 USA; gThe Plus Group, Albuquerque, NM 87112 USA
}

\begin{abstract}
The following topics related to radionuclide and colloid transport in the Culebra Dolomite in the 1996 performance assessment for the Waste Isolation Pilot Plant (WIPP) are presented: (i) mathematical description of models, (ii) uncertainty and sensitivity analysis results arising from subjective (i.e., epistemic) uncertainty for individual releases, and (iii) construction of complementary cumulative distribution functions (CCDFs) arising from stochastic (i.e., aleatory) uncertainty. The presented results indicate that radionuclide and colloid transport in the Culebra Dolomite does not constitute a serious threat to the effectiveness of the WIPP as a disposal facility for transuranic waste. Even when the effects of uncertain analysis inputs are taken into account, no radionuclide transport to the boundary with the accessible environment was observed; thus the associated CCDFs for comparison with the boundary line specified in the U.S. Environmental Protection Agency's standard for the geologic disposal of radioactive waste (40 CFR 191, 40 CFR 194) are degenerate in the sense of having a probability of zero of exceeding a release of zero.
\end{abstract}

Key Words: Aleatory uncertainty, compliance certification application, Culebra Dolomite, epistemic uncertainty, Latin hypercube sampling, Monte Carlo, performance assessment, risk, radioactive waste, radionuclide transport, stochastic uncertainty, subjective uncertainty, transuranic waste, Waste Isolation Pilot Plant, 40 CFR 191, 40 CFR 194.

Please send page proof to:

Jon C. Helton

Department 6848, MS 0779

Sandia National Laboratories

Albuquerque, NM 87185-0779, USA

Phone: 505-284-4808

Fax: 505-844-2348

email: JCHELTO@sandia.gov 


\section{DISCLAIMER}

This report was prepared as an account of work sponsored by an agency of the United States Government. Neither the United States Government nor any agency thereof, nor any of their employees, make any warranty, express or implied, or assumes any legal liability or responsibility for the accuracy, completeness, or usefulness of any information, apparatus, product, or process disclosed, or represents that its use would not infringe privately owned rights. Reference herein to any specific commercial product, process, or service by trade name, trademark, manufacturer, or otherwise does not necessarily constitute or imply its endorsement, recommendation, or favoring by the United States Government or any agency thereof. The views and opinions of authors expressed herein do not necessarily state or reflect those of the United States Government or any agency thereof. 


\section{DISCLAIMER}

Portions of this document may be illegible in electronic image products. Images are produced from the best available original document. 


\section{Introduction}

The Waste Isolation Pilot Plant (WIPP) is under development by the U.S. Department of Energy (DOE) for the geologic disposal of transuranic waste. This article describes modeling procedures and results for fluid flow and radionuclide transport in the Culebra Dolomite, which overlies the bedded salt formation (i.e., the Salado Fm) in which waste disposal will take place and is also the most permeable potential pathway by which radionuclides might be transported away from their original disposal location. Further, descriptions are given for procedures developed to construct complementary cumulative distribution functions (CCDFs) for radionuclide transport through the Culebra to the accessible environment for comparison with U.S. Environmental Protection Agency's (EPA's) standard for the geologic disposal of radioactive waste. ${ }^{1-4}$ The presented models and results constitute part of the 1996 performance assessment (PA) for the WIPP and support a compliance certification application (CCA) by the DOE to the EPA for the certification of the WIPP for the disposal of transuranic waste. ${ }^{5}$

At a conceptual level, the 1996 WIPP PA is underlain by three entities (EN1, EN2, EN3): EN1, a probabilistic characterization of the likelihood of different futures occurring at the WIPP site over the next 10,000 yr (Sect. 3, Ref. 6); EN2, a procedure for estimating the radionuclide releases to the accessible environment associated with each of the possible futures that could occur at the WIPP site over the next 10,000 yr (Sect. 4, Ref. 6); and EN3, a probabilistic characterization of the uncertainty in the parameters used in the definitions of EN1 and EN2 (Sect. 5, Ref. 6). All three of these entities play a role in the Culebra flow and transport results presented in this article. In particular, the following topics are considered: (i) models for fluid flow and radionuclide transport in the Culebra, which constitute part of EN2 (Sect. 4, Ref. 6); (ii) construction of CCDFs for radionuclide transport through the Culebra to the accessible environment, which involves the probability space $\left(\mathrm{S}_{s t}, \&{ }_{s t}, p_{s t}\right)$ for stochastic uncertainty associated with EN1 (Sect. 3, Ref. 6; Ref. 7); and (iii) uncertainty and sensitivity analysis to assess the implications of uncertain analysis inputs, which involves the probability space $\left(\mathrm{S}_{s u}, \& s u, p_{s u}\right)$ for subjective uncertainty associated with EN3 (Sect. 5, Ref. 6; Ref. 8).

When viewed formally, EN2 is defined by a function $f$ of the form

$$
\begin{aligned}
f\left(\mathbf{x}_{s t}\right)= & f_{C}\left(\mathbf{x}_{s t}\right)+f_{S P}\left[\mathbf{x}_{s t}, f_{B}\left(\mathbf{x}_{s t}\right)\right]+f_{D B R}\left\{\mathbf{x}_{s t}, f_{S P}\left[\mathbf{x}_{s t}, f_{B}\left(\mathbf{x}_{s t}\right)\right], f_{B}\left(\mathbf{x}_{s t}\right)\right\} \\
& +f_{M B}\left[\mathbf{x}_{s t}, f_{B}\left(\mathbf{x}_{s t}\right)\right]+f_{D L}\left[\mathbf{x}_{s t}, f_{B}\left(\mathbf{x}_{s t}\right)\right]+f_{S}\left[\mathbf{x}_{s t}, f_{B}\left(\mathbf{x}_{s t}\right)\right] \\
& +f_{S-T}\left\{\mathbf{x}_{s t, 0}, f_{S-F}\left(\mathbf{x}_{s t, 0}\right), f_{N-P}\left[\mathbf{x}_{s t}, f_{B}\left(\mathbf{x}_{s t}\right)\right]\right\},
\end{aligned}
$$

where $\mathbf{x}_{s t} \sim$ particular future under consideration, $\mathbf{x}_{s t, 0} \sim$ future involving no drilling intrusions but a mining event at the same time $t_{\min }$ as in $\mathbf{x}_{s t}, f_{C}\left(\mathbf{x}_{s t}\right) \sim$ cuttings and cavings release to accessible environment for $\mathbf{x}_{s t}$ calculated with 
CUTTINGS_S, $f_{B}\left(\mathbf{x}_{s t}\right) \sim$ two-phase flow results calculated for $\mathbf{x}_{s t}$ with BRAGFLO (in practice, $f_{B}\left(\mathbf{x}_{s t}\right)$ is a vector containing a large amount of information), $f_{S P}\left[\mathbf{x}_{s t}, f_{B}\left(\mathbf{x}_{s t}\right)\right] \sim$ spallings release to accessible environment for $\mathbf{x}_{s t}$ calculated with the spallings model contained in CUTTINGS_S (this calculation requires BRAGFLO results (i.e., $\left.f_{B}\left(\mathbf{x}_{s t}\right)\right)$ as input), $f_{D B R}\left\{\mathbf{x}_{s t}, f_{S P}\left[\mathbf{x}_{s t}, f_{B}\left(\mathbf{x}_{s t}\right)\right], f_{B}\left(\mathbf{x}_{s t}\right)\right\} \sim$ direct brine release to accessible environment for $\mathbf{x}_{s t}$ calculated with a modified version of BRAGFLO designated BRAGFLO_DBR (this calculation requires spallings results obtained from CUTTINGS_S (i.e., $f_{S P}\left[\mathbf{x}_{s t}, f_{B}\left(\mathbf{x}_{s t}\right)\right]$ ) and BRAGFLO results (i.e., $f_{B}\left(\mathbf{x}_{s t}\right)$ ) as input), $f_{M B}\left[\mathbf{x}_{s t}, f_{B}\left(\mathbf{x}_{s t}\right)\right] \sim$ release through anhydrite marker beds to accessible environment for $\mathbf{x}_{s t}$ calculated with NUTS (this calculation requires BRAGFLO results (i.e., $f_{B}\left(\mathbf{x}_{s t}\right)$ ) as input), $f_{D L}\left[\mathbf{x}_{s t}, f_{B}\left(\mathbf{x}_{s t}\right)\right] \sim$ release through Dewey Lake Red Beds to accessible environment for $\mathbf{x}_{s t}$ calculated with NUTS (this calculation requires BRAGFLO results (i.e., $\left.f_{B}\left(\mathbf{x}_{s t}\right)\right)$ as input), $f_{S}\left[\mathbf{x}_{s t}, f_{B}\left(\mathbf{x}_{s t}\right)\right] \sim$ release to land surface due to brine flow up a plugged borehole for $\mathbf{x}_{s t}$ calculated with NUTS or PANEL (this calculation requires BRAGFLO results (i.e., $f_{B}\left(\mathbf{x}_{S t}\right)$ ) as input), $f_{S-F}\left(\mathbf{x}_{s t, 0}\right) \sim$ Culebra flow field calculated for $\mathbf{x}_{s t, 0}$ with SECOFL2D, $f_{N-P}\left[\mathbf{x}_{s t}, f_{B}\left(\mathbf{x}_{s t}\right)\right] \sim$ release to Culebra for $\mathbf{x}_{s t}$ calculated with NUTS or PANEL as appropriate (this calculation requires BRAGFLO results (i.e., $f_{B}\left(\mathbf{x}_{s t}\right)$ ) as input), $f_{S-T}\left\{\mathbf{x}_{s t, 0}, f_{S-F}\left(\mathbf{x}_{s t, 0}\right), f_{N-P}\left[\mathbf{x}_{s t}, f_{B}\left(\mathbf{x}_{s t}\right)\right]\right\} \sim$ groundwater transport release through Culebra to accessible environment calculated with SECOTP2D (this calculation requires SECOFL2D results (i.e., $f_{S-F}\left(\mathbf{x}_{s t, 0}\right)$ ) and NUTS or PANEL results (i.e., $\left.f_{N-P}\left[\mathbf{x}_{s t}, f_{B}\left(\mathbf{x}_{s t}\right)\right]\right)$ as input; $\mathbf{x}_{s t, 0}$ is used as an argument to $f_{S-T}$ because drilling intrusions are assumed to cause no perturbations to the flow field in the Culebra) (Sect. 4, Ref. 6).

The function $f_{S-F}$ in Eq. (1) corresponds to the model used for fluid (i.e., brine) flow in the Culebra in the 1996 WIPP PA, with the computational evaluation of this model being carried out by the SECOFL2D program (Fig. 2, Table 2, Ref. 6). Similarly, the function $f_{S-T}$ in Eq. (1) corresponds to the model used for radionuclide transport in the Culebra, with the computational evaluation of this model being carried out by the SECOTP2D program (Fig. 2, Table 2, Ref. 6). The models used for the fluid flow and radionuclide transport in SECOFL2D and SECOTP2D are described in Sects. 2-5 and 6-7, respectively. The mathematical formulations of the other functions appearing in Eq. (1) (i.e., $f_{C}, f_{B}, f_{S P}, f_{D B R}, f_{M B}, f_{D L}, f_{S}, f_{N-P}$ ) are described in additional articles. ${ }^{9-12}$ Further, a computational strategy used to reduce the cost of radionuclide transport calculations is described in Sect. 9.

At a conceptual level, evaluation of the CCDF for radionuclide transport through the Culebra to the accessible environment involves evaluation of the following integral (Sect. 4, Ref. 6):

$$
\operatorname{prob}_{S-T}(R e l>R)=\int_{S_{s t}} \delta_{R}\left[f_{S-T}\left\{\mathbf{x}_{s t, 0}, f_{S-F}\left(\mathbf{x}_{s t, 0}\right), f_{N-P}\left[\mathbf{x}_{s t}, f_{B}\left(\mathbf{x}_{s t}\right)\right]\right\}\right] d_{s t}\left(\mathbf{x}_{s t}\right) d V_{s t},
$$

where $\delta_{R}\left[f_{S-T}(\sim)\right]=1$ if $f_{S-T}(\sim)>R$ and 0 if $f_{S-T}(\sim) \leq R, d_{S t}$ is the density function associated with the probability space $\left(\mathrm{S}_{s t}, \&_{s t}, p_{s t}\right)$ for stochastic uncertainty (Sect. 3, Ref. 6; Ref. 7), and prob pr-T $\left._{(R e l}>R\right)$ is the probability that 
a release greater than size $R$ will occur. Typically, $R$ is expressed in the normalized units defined by the EPA (Eq. (1), Ref. 6), although other possibilities exist (e.g., Ci's or Bq's if releases of individual radionuclides are under consideration). In practice, the preceding integral is too complex to allow a closed-form evaluation. As a result, the 1996 WIPP PA uses the Monte Carlo procedure indicated below to estimate this integral (Sect. 4, Ref. 6; Sects. 10, 11, Ref. 7):

$$
\operatorname{prob}_{S-T}(\operatorname{Rel}>R)=\sum_{i=1}^{n S} \delta_{R}\left[f_{S-T}\left\{\mathbf{x}_{s t, 0}, f_{S-F}\left(\mathbf{x}_{s t, 0}\right), f_{N-P}\left[\mathbf{x}_{s t, i}, f_{B}\left(\mathbf{x}_{s t, i}\right)\right]\right\}\right] / n S
$$

where the $\mathbf{x}_{s t, i}, i=1,2, \ldots, n S=10,000$, correspond to a random sample of size $n S=10,000$ from the sample space $\mathrm{S}_{s t}$ associated with the probability space $\left(\mathrm{S}_{s t}, \& \quad s t, p_{s t}\right)$ for stochastic uncertainty. The evaluation of the preceding approximation to produce a CCDF for radionuclide transport through the Culebra to the accessible environment is discussed in Sect. 9. The construction of CCDFs for the other release modes is discussed in additional articles. $9,11-13$

When the effects of imprecisely known analysis inputs are included, the representations for $f_{S-F}$ and $f_{S-T}$ in Eq. (1) will also contain a dependence on $\mathbf{x}_{s u}$, where $\mathbf{x}_{s u}$ is an element of the sample space $\mathrm{S}_{s u}$ associated with the probability space $\left(\mathrm{S}_{s u}, \& \quad s u, p_{s u}\right)$ for subjective uncertainty (Sect. 5, Ref. 6; Ref. 8). The possible values for $\mathbf{x}_{s u}$ lead to distributions of flow and transport results for both specific futures $\mathbf{x}_{s t}$ and also for the CCDFs that result from integrating over all possible values for $\mathbf{x}_{s t}$. In the 1996 WIPP PA, these distributions are approximated by using Latin hypercube sampling ${ }^{14}$ to generate a mapping from $\mathrm{S}_{s u}$ to analysis outcomes of interest (Sect. 5, Ref. 6; Sect. 8, Ref. 8). The generation and presentation of this mapping is usually referred to as uncertainty analysis. Once generated, this mapping can be explored with sensitivity analysis techniques based on examination of scatterplots, regression analysis, and correlation analysis (Sect. 3.5, Ref. 15). Uncertainty and sensitivity analysis results for fluid flow and radionuclide transport are presented in Sects. 8 and 12, respectively. No radionuclide transport to the boundary with the accessible environment was observed, with the result that the CCDFs for comparison with the boundary line specified in the EPA standard for the geologic disposal of radioactive waste are degenerate in the sense of having a probability of zero of exceeding a release of zero (Sect. 11). Uncertainty and sensitivity analysis results for the other release modes are available in other articles. ${ }^{9}, 11-13,16,17$

This article is based on material contained in Sect. 4.8, Sect. 4.9 and Chapt. 12 of Ref. 18.

\section{SECOFL2D: Mathematical Description}

Groundwater flow in the Culebra Dolomite is represented by the equation 


$$
S\left(\frac{\partial h}{\partial t}\right)=\nabla \cdot(b \mathbf{K} \nabla h)-Q
$$

where $S=$ medium storativity (dimensionless), $h=$ hydraulic head $(\mathrm{m}), t=$ time $(\mathrm{s}), b=$ aquifer thickness (m), $\mathbf{K}=$ hydraulic conductivity tensor $(\mathrm{m} / \mathrm{s})$, and $Q=$ source/sink term expressed as the volumetric flux per unit area $\left(\left(\mathrm{m}^{3} / \mathrm{m}^{2}\right) / \mathrm{s}=\mathrm{m} / \mathrm{s}\right)$. Further, the Culebra is assumed to be isotropic, and as a result, $\mathbf{K}$ is defined by

$$
\mathbf{K}(x, y)=k(x, y)\left[\begin{array}{ll}
1 & 0 \\
0 & 1
\end{array}\right]
$$

where $k(x, y)$ is the hydraulic conductivity $(\mathrm{m} / \mathrm{s})$ at the point $(x, y)$.

The following additional simplifying assumptions are also made: fluid flow in the Culebra is at steady state (i.e., $\partial h / \partial t=0$ ), and source/sink effects arising from borehole intrusions and infiltration are negligible (i.e., $Q=0$ ). Given these assumptions, Eq. (4) simplifies to

$$
\nabla \bullet(b K \nabla h)=0
$$

which is the equation actually solved to obtain fluid flow (i.e., KVh) in the Culebra. In the 1996 WIPP PA, $b=4 \mathrm{~m}$ (Ref. 19), and $k(x, y)$ in Eq. (5) is a function of an imprecisely known transmissivity field as discussed in Sect. 3.

\section{SECOFL2D: Implementation}

The first step in the analysis of fluid flow in the Culebra was to generate transmissivity fields $t(x, y)\left(\mathrm{m}^{2} / \mathrm{s}\right)$ for the Culebra and to characterize the uncertainty in these fields. This was accomplished by generating a large number of plausible transmissivity fields with WIPP-site data and geostatistical analysis with the program GRASP-INV. ${ }^{20}$ Each generated transmissivity field $T(x, y)$ is a representation of spatial variability of transmissivity in the Culebra that is consistent with measured field data. A total of 100 equally plausible transmissivity fields were generated for use in the analysis and correspond to the variable CTRAN in Table 1 of Ref. 8.

The hydraulic conductivity $k(x, y)$ in Eq. (5) was defined in terms of the transmissivity fields $t(x, y)$ by

$$
k(x, y)=T(x, y) / b .
$$

Flow was assumed to take place primarily in the lower $4 \mathrm{~m}$ of the Culebra ${ }^{19}$ and so a value of $b=4 \mathrm{~m}$ was used in Eq. (7), which results in a conservation of transmissivity.

Fluid flow (i.e., $\mathrm{K} \nabla h$ ) is determined by solving Eq. (6) for two different cases ${ }^{21}$ : (i) mining of potash deposits outside the land withdrawal boundary (Fig. 1), and (ii) mining of potash deposits inside and outside the land 
withdrawal boundary (Fig. 2). As specified by guidance in 40 CFR 194 (p. 5229, Ref. 3), potash mining increases the hydraulic conductivity in the Culebra in the vicinity of such mining by an uncertain factor with a value between 1 and 1000 (see CTRANSFM in Table 1 of Ref. 8). The mining of economic potash reserves outside the land withdrawal boundary (Fig. 1) is assumed to have always occurred by $100 \mathrm{yr}$ after decommissioning of the WIPP (i.e., by the end of the assumed 100 yr period of active institutional control). As specified in 40 CFR 194.32(b), the occurrence of potash mining within the land withdrawal boundary (Fig. 2) follows a Poisson process with a rate constant of $\lambda_{m}=1 \times 10^{-4} \mathrm{yr}^{-1}$ (see Sect. 7, Ref. 7).

The preceding cases result in the following two modifications of the definition of $k(x, y)$ in Eq. (7):

$$
\begin{aligned}
& k_{1}(x, y)= \begin{cases}S F M k(x, y) & \text { if }(x, y) \text { corresponds to a point impacted by mining in Fig. } 1 \\
k(x, y) & \text { otherwise, }\end{cases} \\
& k_{2}(x, y)= \begin{cases}S F M k(x, y) & \text { if }(x, y) \text { corresponds to a point impacted by mining in Fig. } 2 \\
k(x, y) & \text { otherwise, }\end{cases}
\end{aligned}
$$

where $S F M$ is the scale factor for hydraulic conductivity due to potash mining that is specified in 40 CFR 194 (p. 5229, Ref. 3; see CTRANSFM in Table 1, Ref. 8).

In turn, $k_{1}(x, y)$ and $k_{2}(x, y)$ result in the following definitions for the hydraulic conductivity tensor $\mathbf{K}$ :

$$
\mathbf{K}_{i}(x, y)=k_{i}(x, y)\left[\begin{array}{ll}
1 & 0 \\
0 & 1
\end{array}\right], \quad i=1,2
$$

In the analysis, Eq. (6) is solved with each of the preceding definitions of $\mathrm{K}_{i}$ to obtain characterizations of fluid flow in the Culebra under partially-mined conditions (i.e., $\mathbf{K}_{1} \nabla h$ ) and fully-mined conditions (i.e., $\mathbf{K}_{2} \nabla h$ ).

The determination of fluid flow in the Culebra through the solution of Eq. (6) does not incorporate the potential effects of climate change on fluid flow. Such effects are incorporated into the analysis by the use of an uncertain scale factor (see CULCLIM in Table 1 of Ref. 8) to introduce the potential effects of climate change into the analysis. ${ }^{22,23}$ Specifically, the Darcy fluid velocity $\mathbf{v}_{i}(x, y)$ actually used in the radionuclide transport calculations is given by

$$
\mathbf{v}_{i}(x, y)=\left[u_{i}(x, y), v_{i}(x, y)\right]=S F C\left[\mathbf{K}_{i}(x, y) \nabla h_{i}(x, y)\right]^{T},
$$

where $u_{i}(x, y)$ and $v_{i}(x, y)$ represent Darcy fluid velocities $(\mathrm{m} / \mathrm{s})$ at the point $(x, y)$ in the $x$ and $y$ directions, respectively, $\nabla h_{i}(x, y)$ is obtained from Eq. (6) with $\mathbf{K}=\mathbf{K}_{i}$, and $S F C$ is a scale factor used to incorporate the uncertainty that results from possible climate changes (see CULCLIM in Table 1 of Ref. 8). 


\section{SECOFL2D: Computational Grids and Boundary Value Conditions}

The representation for fluid flow in the Culebra in Eq. (6) is evaluated on both a regional and a local scale (Fig. 3). The regional scale simulations were performed over a large problem domain (Fig. 3) and used a relatively coarse computational grid (Fig. 4). The results of the regional scale simulations were used to define boundary value conditions for the local scale simulations. This analysis approach allows the use of a high resolution computational grid (Fig. 5) in the region of interest (i.e., close to the repository), and the incorporation of natural flow boundaries on a much larger scale.

The regional domain is approximately $22 \times 30 \mathrm{~km}$ and aligned with the axis of Nash Draw along a portion of the western boundary (Fig. 3). Nash Draw is a topographic low created by the dissolution of halite beneath the Rustler Formation. As a consequence of this dissolution, the Rustler has subsided and the contact between the Rustler and Salado Formations consists of an unstructured residuum of gypsum, clay, and sandstone. This residuum is highly conductive and known to discharge to the surface into saline lakes. ${ }^{24}$ Test wells in the southern portion of Nash Draw produced brine from this interval, and it has become known as the brine aquifer. ${ }^{25}$ Robinson and Lang 1938 described the brine aquifer and suggested that the structural conditions that caused the development of Nash Draw may control the occurrence of brine. Thus, the brine aquifer boundary may coincide with the topographic surface elevations of Nash Draw. Drilling associated with the WIPP hydrogeologic studies in the northern half of Nash Draw support this theory (p. 50, Ref. 26).

Groundwater divides are boundaries across which it is assumed that no groundwater flow occurs. The known topographic and geologic discharge features of Nash Draw suggest that it is a groundwater divide. Thus, the axis of Nash Draw is assumed to behave hydraulically as a discharge-type groundwater divide. Consequently, the portion of the western boundary of the regional domain (Figs. 3,4) oriented along the axis of Nash Draw is modeled using a no flow boundary condition (Table 1).

The remaining regional boundary conditions are not as well defined. When possible, they were positioned to align with topographic highs or other geologic features such as San Simon Swale on the northeastern boundary (Fig. 3). Due to their uncertainty, the boundaries are positioned a large distance from the local problem domain (Fig. 3). Due to the relative abundance of head data near the site, Dirichlet (i.e., constant head) boundary conditions were imposed at all boundary locations other than Nash Draw and the northeastern corner of the problem domain (Table 1). No-flow boundary conditions were assumed in the northeastern corner due to low transmissivities and the coincidence with San Simon Swale, another topographic low (Table 1).

The boundary value conditions in Table 1 were used in all solutions of Eq. (6) on the regional domain in Figs. 3 and 4. As steady state solutions were being calculated, there was no need to specify initial value conditions. 
The local domain boundaries (Fig. 5) were selected to capture important flow paths and facilitate the computation of integrated discharges across the land withdrawal boundary. The local domain is approximately $7 \times 7$ km. The computational grid contains 75 columns and 65 rows, resulting in 4875 grid blocks. Dirichlet (i.e., constant head) boundary conditions were imposed on the local domain and were derived from the solution for $h$ on the regional domain with a bi-linear interpolation procedure. Unlike the constant head boundary conditions on the regional domain, the constant head boundary conditions on the local domain change for each calculation due to changes in value for $\mathbf{K}=\mathbf{K}_{i}$. As for the regional domain, steady state solutions to Eq. (6) were calculated on the local domain and so there was no need to specify initial value conditions.

\section{SECOFL2D: Numerical Solution}

The flow model in Eq. (6) is evaluated with a second-order difference procedure ${ }^{27,28}$ on the computational grids in Figs. 4 and 5. Specifically, the discretized form of Eq. (6) is

$$
\begin{aligned}
0= & \frac{1}{\Delta x_{i}}\left[\frac{T_{i+1 / 2, j}\left(h_{i+1, j}-h_{i, j}\right)}{\left(\Delta x_{i+1}+\Delta x_{i}\right) / 2}-\frac{T_{i-1 / 2, j}\left(h_{i, j}-h_{i-1, j}\right)}{\left(\Delta x_{i}+\Delta x_{i-1}\right) / 2}\right] \\
& +\frac{1}{\Delta y_{j}}\left[\frac{T_{i, j+1 / 2}\left(h_{i, j+1}-h_{i, j}\right)}{\left(\Delta y_{j+1}+\Delta y_{j}\right) / 2}-\frac{T_{i, j-1 / 2}\left(h_{i, j}-h_{i, j-1}\right)}{\left(\Delta y_{j}+\Delta y_{j-1}\right) / 2}\right]
\end{aligned}
$$

where

$$
\begin{aligned}
& T_{i j}=b_{i j} k_{i j}, T_{i-1 / 2, j}=2 T_{i j} T_{i-1, j} /\left(T_{i j}+T_{i-1, j}\right), T_{i+1 / 2, j}=2 T_{i+1, j} T_{i j} /\left(T_{i+1, j}+T_{i j}\right) \\
& T_{i, j-1 / 2}=2 T_{i j} T_{i, j-1} /\left(T_{i j}+T_{i, j-1}\right), T_{i, j+1 / 2}=2 T_{i, j+1} T_{i j} /\left(T_{i, j+1}+T_{i j}\right)
\end{aligned}
$$

and $b_{i j}$ and $k_{i j}$ are the aquifer height (Eq. (4)) and hydraulic conductivity (Eq. (5)) at node (i,j). In the 1996 WIPP $\mathrm{PA}, b_{i j}=4 \mathrm{~m}$ and $k_{i j}$ enters the analysis through the specification of an uncertain, spatially variable transmissivity (see Eqs. (7) - (9)).

The determination of $h$ is then completed by the solution of the linear system of equations in Eq. (12) for the unknown heads $h_{i j}$. This solution is accomplished by using a semi-coarsening multigrid solver ${ }^{29-30}$ to make an initial estimate of the solution of the system in Eq. (12). Then, this estimate is used as the starting point in the construction of the solution by a successive over-relaxation (SOR) iterative method. ${ }^{28}$ As the $h_{i j}$ are determined, the Darcy velocities in Eq. (11) are also obtained and saved for use in later radionuclide transport calculations. Additional information on the numerical procedures in use is available in the user's manual for SECOFL2D (Sects. $3.1-3.3$, Ref. 31). 
Additional information on SECOFL2D and its use in the 1996 WIPP PA to determine fluid flow patterns in the Culebra Dolomite can be found in the SECOFL2D users manual ${ }^{31}$ and in the analysis package for fluid flow and radionuclide transport in the Culebra Dolomite. ${ }^{32}$

\section{SECOTP2D: Mathematical Description}

A dual porosity model is used to represent radionuclide transport in the Culebra Dolomite. ${ }^{19}$ In this model, one system of partial differential equations (see Eq. (13)) is used to represent radionuclide transport in fractures within the Culebra Dolomite (i.e., advective transport) and another system of partial differential equations (see Eq. (18)) is used to represent radionuclide movement and sorption in the matrix that surrounds the fractures (i.e., diffusive transport).

The system used to represent advective transport in fractures is given by ${ }^{33}$

$$
\nabla \cdot\left[\phi \mathbf{D}_{k} \nabla C_{k}-\mathbf{v} C_{k}\right]=\phi R_{k}\left(\frac{\partial C_{k}}{\partial t}\right)+\phi R_{k} \lambda_{k} C_{k}-\phi R_{k-1} \lambda_{k-1} C_{k-1}-Q_{k}-\Gamma_{k}
$$

for $k=1,2, \ldots, n R$, where $n R=$ number of radionuclides under consideration, $C_{k}=$ concentration of radionuclide $k$ in brine $\left(\mathrm{kg} / \mathrm{m}^{3}\right), \mathbf{D}_{k}=$ hydrodynamic dispersion tensor $\left(\mathrm{m}^{2} / \mathrm{s}\right), \mathbf{v}=$ Darcy velocity (i.e., specific discharge) of brine $\left(\mathrm{m} / \mathrm{s}=\left(\mathrm{m}^{3} / \mathrm{m}^{2}\right) / \mathrm{s}\right), \phi=$ advective (i.e., fracture) porosity (dimensionless), $R_{k}=$ advective retardation coefficient (dimensionless), $\lambda_{k}=$ decay constant for radionuclide $k\left(\mathrm{~s}^{-1}\right), Q_{k}=$ injection rate of radionuclide $k$ per unit bulk volume of formation $\left((\mathrm{kg} / \mathrm{s}) / \mathrm{m}^{3}\right)$ (Note: $Q_{k}>0$ corresponds to injection into the fractures), and $\Gamma_{k}=$ mass transfer rate of radionuclide $k$ per unit bulk volume of formation due to diffusion between fractures and surrounding matrix $\left((\mathrm{kg} / \mathrm{s}) / \mathrm{m}^{3}\right)$ (Note: $\Gamma_{k}>0$ corresponds to diffusion into fractures). The Darcy velocity $\mathbf{v}$ is obtained from the solution of Eq. (6); specifically, $v$ is defined by the relationship in Eq. (11). The advective (i.e., fracture) porosity $\phi$ is an uncertain analysis input (Ref. 34; see CFRCPOR in Table 1, Ref. 8).

The hydrodynamic dispersion tensor is defined by 33,35

$$
\mathbf{D}_{k}=\frac{1}{\|\mathbf{v}\| \phi}\left[\begin{array}{rr}
u & -v \\
v & u
\end{array}\right]\left[\begin{array}{cc}
\alpha_{L} & 0 \\
0 & \alpha_{T}
\end{array}\right]\left[\begin{array}{cc}
u & v \\
-v & u
\end{array}\right]+\tau D_{k}^{*}\left[\begin{array}{ll}
1 & 0 \\
0 & 1
\end{array}\right]
$$

where $\alpha_{L}$ and $\alpha_{T}$ are the longitudinal and transverse dispersivities (m); $u$ and $v$ are the $x$ and $y$ components of $v$ (i.e., $\mathbf{v}=[u, v]) ; D_{k}^{*}$ is the free water molecular diffusion coefficient $\left(\mathrm{m}^{2} \mathrm{~s}^{-1}\right)$ for radionuclide $k$, and $\tau=L / L_{e}$ is the advective tortuosity, where $L$ denotes the length of the porous medium (m) and $L_{e}$ denotes the flow path length of a fluid particle (m). In the 1996 WIPP PA, $\alpha_{L}=\alpha_{T}=0 \mathrm{~m}$ (Ref. 36). The diffusion coefficient $D_{k}^{*}$ equals $3 \times 10^{-10}$ $\mathrm{m}^{2} / \mathrm{s}$ for radionuclides in the +3 oxidation state (i.e., $\mathrm{Am}^{+3}, \mathrm{Pu}^{+3}$ ), $1.53 \times 10^{-10} \mathrm{~m}^{2} / \mathrm{s}$ for radionuclides in the +4 
oxidation state (i.e., $\mathrm{Pu}^{+4}, \mathrm{Th}^{+4}, \mathrm{U}^{+4}$ ) and $4.26 \times 10^{-10} \mathrm{~m}^{2} / \mathrm{s}$ for radionuclides in the +6 oxidation state (i.e., $\mathrm{U}^{+6}$ ) (Ref. 37); the existence of plutonium in the +3 or +4 oxidation state (i.e., as $\mathrm{Pu}^{+3}$ or $\mathrm{Pu}^{+4}$ ) and the existence of uranium in the +4 or +6 oxidation state (i.e., as $\mathrm{U}^{+4}$ or $\mathrm{U}^{+6}$ ) is determined by an uncertain analysis input (see WOXSTAT in Sect. 5.2) (Ref. 37). Further, $\tau=1$ (Ref. 38). Thus, the definition of $\mathbf{D}_{k}$ reduces to

$$
\mathbf{D}_{k}=D_{k}^{*}\left[\begin{array}{ll}
1 & 0 \\
0 & 1
\end{array}\right]
$$

in the 1996 WIPP PA.

The advective retardation coefficient $R_{k}$ is defined by

$$
R_{k}=1+(1-\phi) \rho_{A} K_{A k} / \phi
$$

where $\rho_{A}=$ surface area density of fractures in Culebra $\left(\mathrm{m}^{2} / \mathrm{m}^{3}=1 / \mathrm{m}\right)$ (i.e., surface area of fractures $\left(\mathrm{m}^{2}\right)$ divided by volume of fractures $\left.\left(\mathrm{m}^{3}\right)\right)$, and $K_{A k}=$ surface area distribution coefficient $\left(\left(\mathrm{kg} / \mathrm{m}^{2}\right) /\left(\mathrm{kg} / \mathrm{m}^{3}\right)=\mathrm{m}\right)$ (i.e., concentration of radionuclide $k$ sorbed on fracture surfaces $\left(\mathrm{kg} / \mathrm{m}^{2}\right)$ divided by concentration of radionuclide $k$ dissolved in brine within fractures $\left(\mathrm{kg} / \mathrm{m}^{3}\right)$ ). In the 1996 WIPP PA, $K_{A k}=0 \mathrm{~m}$ and thus $R_{k}=1$ (Ref. 39).

The $n R=5$ radionuclides intended for transport in the Culebra (i.e., ${ }^{241} \mathrm{Am},{ }^{238} \mathrm{Pu} \rightarrow{ }^{234} \mathrm{U} \rightarrow{ }^{230} \mathrm{Th},{ }^{239} \mathrm{Pu}$ ) are discussed in Sect. 3 of Ref. 12 (see Eq. (21), Table 3, Ref. 12). Due to its short half life (i.e., 88 yr) and the fact that no transport to the accessible environment was observed for the much longer-lived ${ }^{239} \mathrm{Pu}$ (i.e., half life $=24,100 \mathrm{yr}$ ), no Culebra transport calculations were carried out for ${ }^{238} \mathrm{Pu}$. In concept, the term $Q_{k}$ in Eq. (13) provides the link between the releases to the Culebra calculated with NUTS and PANEL (Ref. 12) and transport within the Culebra. In the computational implementation of the 1996 WIPP PA, radionuclide transport calculations in the Culebra were performed for unit radionuclide releases to the Culebra and then the outcomes of these calculations were used to construct the release to the accessible environment associated with time-dependent releases into the Culebra derived from NUTS and PANEL calculations (Sect. 9). The definition of $Q_{k}$ is discussed in more detail in Sect. 7.

If $\mathrm{B}$ denotes an arbitrary boundary (e.g., the land withdrawal boundary) in the domain of Eq. (13) (i.e., Fig. 5), then the cumulative transport of $T_{k}(t, \mathrm{~B})$ of radionuclide $k$ from time 0 to time $t$ across $\mathrm{B}$ is given by

$$
T_{k}(t, \mathrm{~B})=\int_{b}^{t}\left[\int_{\mathrm{B}} b\left\{\mathbf{v}(x, y) C_{k}(x, y, \tau)-\phi \mathbf{D}_{k}(x, y, t) \nabla C_{k}(x, y, \tau)\right\} \bullet \mathbf{n}(x, y) d s\right] d \tau
$$

where $b=4 \mathrm{~m}$ is the thickness of the Culebra assumed for transport calculations ${ }^{19}, \phi$ is a constant in the context of the preceding integral in the 1996 WIPP PA, $\mathbf{n}(x, y)$ is an outward pointing unit normal vector, and $\int_{B} d s$ denotes a line integral over $\mathrm{B}$. 
The system used to represent diffusive transport in the matrix surrounding the fractures is given by ${ }^{34}$

$$
\frac{\partial}{\partial z}\left(\phi^{\prime} D_{k}^{\prime} \frac{\partial C_{k}^{\prime}}{\partial z}\right)=\phi^{\prime} R_{k}^{\prime}\left(\frac{\partial C_{k}^{\prime}}{\partial t}\right)+\phi^{\prime} R_{k}^{\prime} \lambda_{k} C_{k}^{\prime}-\phi^{\prime} R_{k-1}^{\prime} \lambda_{k-1} C_{k-1}^{\prime}
$$

where $z$ is the spatial coordinate in Fig. $7, D_{k}^{\prime}$ is the matrix diffusion coefficient $\left(\mathrm{m}^{2} / \mathrm{s}\right)$ for radionuclide $k$ defined by $D_{k}^{\prime}=D_{k}^{*} \tau^{\prime}$, and $\tau^{\prime}$ is the matrix tortuosity. The remaining terms have the same meaning as those in Eq. (13) except that the prime denotes properties of the matrix surrounding the fractures. The matrix (i.e., diffusive) tortuosity $\tau^{\prime}$ is defined by $\tau^{\prime}=0.11$ (Ref. 40 ). The matrix (i.e., diffusive) porosity $\phi^{\prime}$ is an uncertain input to the analysis (see CMTRXPOR in Table 1, Ref. 8). The matrix retardation $R_{k}^{\prime}$ is defined by

$$
R_{k}^{\prime}=1+\left(1-\phi^{\prime}\right) \rho_{s} K_{d k} / \phi^{\prime}
$$

where $\rho_{s}$ is the particle density $\left(\mathrm{kg} / \mathrm{m}^{3}\right)$ of the matrix and $K_{d k}$ is the distribution coefficient $\left((\mathrm{Ci} / \mathrm{kg}) /\left(\mathrm{Ci} / \mathrm{m}^{3}\right)=\mathrm{m}^{3} / \mathrm{kg}\right)$ for radionuclide $k$ in the matrix. The density $\rho_{s}$ is assigned a value of $2.82 \times 10^{3} \mathrm{~kg} / \mathrm{m}^{3}$ (Ref. 41). The distribution coefficients $K_{d k}$ are uncertain inputs to the analysis and dependent on the uncertain oxidation state of the relevant element (see CMKDAM3, CMKDPU3, CMKDPU4, CMKDTH4, CMKDU4, CMKDU6, WOXSTAT in Table 1, Ref. $8)$.

The initial and boundary value conditions used in the formulation of Eq. (18) are

$$
\begin{aligned}
& C_{k}^{\prime}(x, y, z, 0)=0 \mathrm{~kg} / \mathrm{m}^{3} \\
& \partial C_{k}^{\prime}(x, y, 0, t) / \partial z=0 \mathrm{~kg} / \mathrm{m}^{2} \\
& C_{k}^{\prime}(x, y, B, t)=C_{k}(x, y, t),
\end{aligned}
$$

where $(x, y)$ corresponds to a point in the domain on which Eq. (13) is solved and $B$ is the matrix half block length (m) in Fig. 7 (i.e., $2 B$ is the thickness of the matrix between two fractures). The initial value condition in Eq. (20) says that no radionuclide is present in the matrix at the beginning of the calculation. The boundary value condition in Eq. (21) says that no radionuclide movement can take place across the centerline of a matrix block separating two fractures. The boundary value condition in Eq..(22) says that the dissolved radionuclide concentration in the matrix at the boundary with the fracture is the same as the dissolved radionuclide concentration within the fracture. The matrix half block length $B$ is an uncertain input to the analysis (see CFRCSP in Table 1, Ref. 8).

The linkage between Eqs. (13) and (18) is accomplished through the term $\Gamma_{k}$, with $\Gamma_{k}$ defining the rate at which radionuclide $k$ diffuses across the boundary between a fracture and the adjacent matrix (Fig. 7). Specifically, 


$$
\Gamma_{k}=-\frac{2 \phi}{a}\left(\left.\phi^{\prime} D_{k}^{\prime} \frac{\partial C_{k}^{\prime}}{\partial z}\right|_{z=B}\right),
$$

where $a$ is the fracture aperture (m) defined by

$$
a=\phi B /(1-\phi) .
$$

The linkage term $\Gamma_{k}$ appears directly in Eq. (13); further, it enters Eq. (18) through the specification of the boundary value condition in Eq. (22), with this condition affecting the value of $\partial C_{k}^{\prime} /\left.\partial z\right|_{z=B}$ in the definition of $\Gamma_{k}$ in Eq. (23).

\section{SECOTP2D: Numerical Solution}

Eqs. (13) and (18) are numerically solved using the spatial discretizations in Figs. 5 and 8. The initial and boundary value conditions used for Eq. (18) in this solution are given in Eqs. (20) - (22). For Eq. (13), the initial value condition is

$$
C_{k}(x, y, 0)=0 \mathrm{~kg} / \mathrm{m}^{3} \text {. }
$$

Further, the boundary value conditions for Eq. (13) are defined at individual points on the boundary of the grid in Fig. 5 on the basis of whether the flow vector $v=[u, v]$ is entering the grid or leaving the grid. The following Neumann boundary value condition is imposed at points $(x, y)$ where flow leaves the grid:

$$
\nabla C_{k}(x, y, t) \cdot \mathbf{n}(x, y)=0\left(\mathrm{~kg} / \mathrm{m}^{3}\right) / \mathrm{m}
$$

where $\mathbf{n}(x, y)$ is an outward pointing unit normal vector defined at $(x, y)$. The following Dirichlet boundary value condition is imposed at points $(x, y)$ where flow enters the grid:

$$
C_{k}(x, y, t)=0 \mathrm{~kg} / \mathrm{m}^{3}
$$

As already indicated, Eqs. (13) and (18) were solved for unit radionuclide releases to the Culebra. Specifically, a release of $1 \mathrm{~kg}$ of each radionuclide under consideration was assumed to take place over a time interval from 0 to $50 \mathrm{yr}$, with this release taking place into the computational cell in Fig. 5 with center at the point $(x=3331.5 \mathrm{~m}, y=$ $5173.2 \mathrm{~m}$ ). This cell (i.e., Cell $(35,55)$ is located near the center of the "Waste Panel Area" in Fig. 5 and has dimensions of $50 \mathrm{~m} \times 50 \mathrm{~m}$. Cell $(35,55)$ has a volume $V$ of

$$
V=(50 \mathrm{~m})(50 \mathrm{~m})(4 \mathrm{~m})=1 \times 10^{4} \mathrm{~m}^{3},
$$

where $4 \mathrm{~m}$ is the assumed thickness of the Culebra Dolomite. ${ }^{19}$ As a result, $Q_{k}(x, y, t)$ has the form 


$$
\begin{aligned}
Q_{k}(x, y, t) & \left.=(1 \mathrm{~kg}) /\left[1 \times 10^{4} \mathrm{~m}^{3}\right)(50 \mathrm{yr})\left(3.16 \times 10^{7} \mathrm{~s} / \mathrm{yr}\right)\right] \\
& =6.33 \times 10^{-14}\left(\mathrm{~kg} / \mathrm{m}^{3}\right) / \mathrm{s}
\end{aligned}
$$

for $0 \leq t \leq 50 \mathrm{yr}$ and $(x, y) \in$ Cell $(35,55)$ in Fig. 5 and $Q_{k}(x, y, t)=0\left(\mathrm{~kg} / \mathrm{m}^{3}\right) / \mathrm{s}$ otherwise.

A high level description of the numerical procedures used to solve Eqs. (13) and (18) follows, with more detail available in WIPP PA 1997. The fracture domain is discretized in space using the block centered finite difference method indicated in Fig. 9. In this formulation, cell concentrations are defined at grid block centers while velocities are defined on grid cell faces. Ghost cells are placed outside the problem domain for the purpose of implementing boundary conditions. The dispersive term, $\nabla \bullet\left(\phi \mathbf{D}_{k} \nabla C_{k}\right)$, in Eq. (13) is approximated using a second-order central difference formula ${ }^{42}$, and the advective term, $\nabla \bullet v C_{k}$, is approximated using the Total Variation Diminishing (TVD) method. ${ }^{43}$ Temporal derivatives are approximated using a first-order backwards difference formula.

The TVD method provides a way of accurately resolving advection dominated transport problems without the occurrence of nonphysical oscillations commonly present in second order solutions. This method invokes a weighted upstream differencing scheme that locally adjusts the weighting to prevent oscillatory behavior and maximize solution accuracy. The weighting parameters are known as the TVD flux limiters $\Phi(x, y, r)$, where $r$ is a function of the concentration gradient and direction of flow. In the 1996 WIPP PA, the van Leer TVD limiter was used (p. 1005, Ref. 43), which is defined as

$$
\Phi(x, y, r)=\max \left\{0, \min \left\{2 r, \frac{r+|r|}{1+|r|}\right\}\right\}
$$

At locations where $u$ (i.e., the Darcy velocity in the $x$ direction) is positive, $r$ is defined at the $j-1 / 2, k$ interface by

$$
r_{j-1 / 2, k}=\frac{\partial C /\left.\partial x\right|_{j-3 / 2, k}}{\partial C /\left.\partial x\right|_{j-1 / 2, k}},
$$

and at locations where $u$ is negative, $r$ is defined by

$$
r_{j-1 / 2, k}=\frac{\partial C /\left.\partial x\right|_{j+1 / 2, k}}{\partial C /\left.\partial x\right|_{j-1 / 2, k}}
$$

Similar definitions are made for $r$ at the $j, k-1 / 2$ interface in the $y$-direction with $v$ (i.e., the Darcy velocity in the $y$ direction) used instead of $u$. 
Because $\Phi_{k}$ is a function of $C_{k}$, the discretized set of equations is nonlinear. This nonlinearity is addressed by treating the flux limiters explicitly (i.e., time lagged). Explicit treatment of the limiter functions, however, can lead to oscillatory and sometimes unstable solutions when the Courant number exceeds unity $(\mathrm{Cr}>1)$, where $\mathrm{Cr}$ is defined by

$$
C r_{x}=|u| \Delta t / \phi \Delta x, C r_{y}=|\psi| \Delta t / \phi \Delta y
$$

To avoid this behavior, the application of the TVD method is restricted to regions in which the Courant numbers are less than one. In regions where $C r>1$, a first order full upwinding scheme is invoked, which is unconditionally stable and non-oscillatory.

The discretized form of Eq. (13) can be expressed in a delta formulation as

$$
\left(\mathbf{I}+\mathbf{L}_{x x}+\mathbf{L}_{y y}+\mathbf{S}\right) \Delta \mathbf{C}^{n+1}=\mathbf{R H S}^{n}
$$

where $\mathbf{I}$ is the identity matrix, $\mathbf{L}_{x x}$ and $\mathbf{L}_{y y}$ are finite difference operators in the $x$ and $y$ directions, $\mathbf{S}$ is an implicit source term that accounts for decay and mass transfer between the matrix and the fracture, RHS consists of the right hand side known values at time level $n$, and $\Delta \mathbf{C}^{n+1}=\mathbf{C}^{n+1}-\mathbf{C}^{n}$. Direct inversion of Eq. (34) for a typical Culebra transport problem is very computationally intensive and requires large amounts of memory and CPU time. To reduce these requirements, the operator in Eq. (34) is factored as follows:

$$
\left(\mathbf{I}+\mathbf{L}_{x x}+\alpha_{x} \mathbf{S}\right)\left(\mathbf{I}+\mathbf{L}_{y y}+\alpha_{y} \mathbf{S}\right) \Delta \mathbf{C}^{n+1}=\mathbf{R H S}^{n}
$$

where $\alpha_{x}$ and $\alpha_{y}$ are constants that must sum to one (i.e., $\alpha_{x}+\alpha_{y}=1$ ). The left hand sides in Eqs. (34) and (35) are not equivalent, with the result that the factorization of Eq. (34) in Eq. (35) is referred to as an "approximate factorization." 42 The advantage of approximately factoring Eq. (34) is that the resulting equation consists of the product of two finite difference operators that are easily inverted independently using a tridiagonal solver. Hence, the solution to the original problem is obtained by solving a sequence of problems in the following order:

$$
\begin{aligned}
& \left(\mathbf{I}+\mathbf{L}_{x x}+\alpha_{x} \mathbf{S}\right) \Delta \overline{\mathbf{C}}=\mathbf{R H S}^{n} \\
& \left(\mathbf{I}+\mathbf{L}_{y y}+\alpha_{y} \mathbf{S}\right) \Delta \mathbf{C}^{n+1}=\Delta \overline{\mathbf{C}} \\
& \mathbf{C}^{n+1}=\mathbf{C}^{n}+\Delta \mathbf{C}^{n+1}
\end{aligned}
$$

The equation for matrix transport, Eq. (18), is coupled implicitly to and solved simultaneously with the equation for fracture transport, Eq. (13). Second-order central differencing is used to approximate the spatial derivatives, and 
a first-order backwards differencing is used to approximate temporal derivatives. The implicit coupling is accomplished using a technique developed in Ref. 44. A detailed description of this technique and its implementation in the 1996 WIPP PA is given in the SECOTP2D user's manual (App. I, Ref. 33).

The cumulative transport $T_{k}(t, \mathrm{~B})$ of individual radionuclides across specified boundaries indicated in Eq. (17) is also accumulated during the numerical solution of Eqs. (13) and (18).

Additional information on SECOTP2D and its use in the 1996 WIPP PA to determine radionuclide transport in the Culebra Dolomite can be found in the SECOTP2D users manual ${ }^{33}$ and in the analysis package for fluid flow and radionuclide transport in the Culebra Dolomite. ${ }^{32}$

\section{Fluid Flow in Culebra}

Fluid flow calculations for the Culebra were performed with the SECOFL2D program (Sects. 2 - 5) for three different sets of conditions: no mining, partial mining and full mining. These designations refer to the extent that commercially viable potash reserves in the vicinity of the WIPP are mined. ${ }^{21}$ Specifically, no mining indicates no mining of potash reserves within the region associated with the computational grids used with SECOFL2D and SECOTP2D. Partial and full mining indicate mining all reserves outside the land withdrawal boundary (Fig. 1) and all reserves both inside and outside the land withdrawal boundary (Fig. 2), respectively. Criteria in 40 CFR 194 specify that partial mining shall be assumed to have taken place by time of closure of the repository (i.e., $t=0)$ and also that full mining will take place at time $t_{\min }$ (Sect. 8, Ref. 7). Thus, only calculations for partial and full mining are relevant with respect to assessing compliance with 40 CFR 191. However, flow calculations for no mining were also performed to provide perspective on the results obtained for partial and full mining.

The only sampled variable that affects the no mining calculations with SECOFL2D is CTRAN (Table 1, Ref. 8), which determines the transmissivity field used for the Culebra. For the partially and fully mined cases, the calculations involve two sampled variables: CTRAN and CTRANSFM. The variable CTRANSFM is a multiplier on the parts of the transmissivity field associated with CTRAN that are assumed to be affected by partial and full mining, respectively (Figs. 1, 2; Table 1, Ref. 8). The use of CTRANSFM in the analysis is specified in 40 CFR 194.

SECOFL2D calculations were first performed on a regional computational grid (Fig. 4). Interpolation on the pressures (i.e., heads) obtained from this calculation were then used to set the boundary conditions for calculations on a local grid (Fig. 5). The flow field obtained from the calculation on the local grid was then used as input to SECOTP2D for the radionuclide transport calculations.

As the 1996 WIPP PA used a total of 300 sample elements (Sect. 8, Ref. 8), and calculations were required for both partially and fully mined conditions, 600 pairs (i.e., on regional and local grids) of SECOFL2D calculations 
were required. As a reminder, only 100 unique transmissivity fields were generated for use in the 1996 WIPP PA (Table 1, Ref. 8). These fields are indexed by CTRAN as described in Table 1 of Ref. 8 . However, 600 unique transmissivity fields result from the consideration of full and partial mining and 300 values for the multiplier CTRANSFM. In addition, 100 pairs of calculations were also performed with the assumption of no mining. Specifically, these calculations were performed with the transmissivity fields associated with CTRAN without use of the multiplier defined by CTRANSFM. Given that 40 CFR 194 requires that partial mining be assumed to occur before closure of the repository, only the results for partial and full mining are needed for direct use in CCDF construction.

The actual result of the SECOFL2D calculation that is passed on to SECOTP2D is a spatially dependent velocity vector (i.e., velocity field) $\mathbf{v}(x, y)$. A total of 700 such vector functions were generated. Examples of three of these vector functions are given in Fig. 10.

The presentation and comparison of 700 vector functions is difficult. One way to make such a presentation and comparison is to use summary quantities as surrogates for the vector functions. The flow path and travel time of a nonreactive, nonsorbing particle released into the velocity field defined by $\mathbf{v}(x, y)$ are such summary results and can be calculated by the TRACKER program, which is part of the SECO suite of programs. ${ }^{45}$

Each velocity field $\mathbf{v}(x, y)$ calculated by SECOFL2D results in a different travel path for a nonreactive, nonsorbing particle released at the center of the repository (Fig. 11). The different values for $\mathbf{v}(x, y)$ can result in quite different travel paths. In particular, significant shifting of the travel paths occurs for most sample elements for fully mined conditions.

The velocity fields $\mathbf{v}(x, y)$ can also be compared on the basis of travel times. Specifically, TRACKER was used to obtain travel times in the Culebra from the center of the repository to the boundary with the accessible environment (Fig. 12). The travel times in Fig. 12 were calculated with the porosity of the Culebra set to 1; technically, this means that the travel times were calculated with the Darcy velocity predicted for the Culebra by SECOFL2D rather than with the pore velocity. This is acceptable because the predicted travel times are only useful for comparing the relative effects of different values of $\mathbf{v}(x, y)$ on travel time and are not intended to be indicative of actual travel times within the Culebra. In particular, radionuclide transport within the Culebra is believed to be appropriately represented by a dual porosity model (Sect. 6). The travel times presented in Fig. 12 do not include the effects of rapid flow through the advective medium (i.e., the fractures), diffusion into the surrounding matrix, sorption, or dispersion. Thus, no matter what porosity is used, the resulting travel times do not characterize radionuclide transport in the Culebra. However, the travel times do give an idea as to whether or not the different ways of defining $\mathbf{v}(x, y)$ (i.e., unmined, partially mined, fully mined) speeds up or slows down movement in the Culebra. Rather surprisingly, the unmined conditions tend to give rise to faster travel times than partially mined or fully mined conditions. However, depending on the individual observations, the fastest travel time can be associated 
with any one of the three conditions. Thus, the assumptions about potash mining and its effects on transmissivity specified in 40 CFR 194 do affect transport in the Culebra, but perhaps not in the manner originally expected.

\section{Transport in Culebra: Computational Strategy}

Without careful planning, the computational cost of performing SECOTP2D calculations (Sects. 6, 7) for radionuclide movement in the Culebra would be prohibitive. In concept, a set of calculations is required for each randomly sampled future. As 300 Latin hypercube sample (LHS) elements are under consideration (i.e., 3 replicates of 100 elements each; see Sect. 8, Ref. 8) and 10,000 randomly sampled futures are evaluated for each LHS element, a total of $3 \times 10^{6}$ sets of SECOTP2D calculations result. In addition, 4 radionuclides are considered for transport in the Culebra (i.e., Am-241, Pu-239, U-234, Th-230), with these radionuclides present in both dissolved and colloidal (i.e., humic, microbial, mineral fragment, actinide intrinsic) states; Pu-238 was not transported in the Culebra due to its short half-life. This potentially places an additional multiplier of 15 (i.e., three decay chains and 5 states) on the number of SECOTP2D calculations. Finally, there is the need to alter the Culebra flow field at time $t_{m i n}$, which adds an additional complication to the analysis. The performance of $4.5 \times 10^{7}$ SECOTP2D calculations with time-varying source rates and flow fields was not considered to be an option. Actually, even this number was arrived at by trimming the number of radionuclides and colloidal states to be considered.

A more computationally efficient approach was needed than simply performing every possible calculation. This approach was provided by taking advantage of the linearity of the system of partial differential equations that underlies SECOTP2D. Because of this linearity, transport calculations can be performed for unit releases to the Culebra at $0 \mathrm{yr}$ and then used to construct transport results for arbitrary time-dependent releases into the Culebra. In concept, 16 SECOTP2D calculations are required for each LHS element (Table 2). Radionuclide transport through the Culebra to the accessible environment for each of the 10,000 randomly sampled futures associated with an LHS element can then be constructed from the results of these 16 calculations (Table 2). Colloidally transported radionuclides are assumed to remain associated with their colloid carriers throughout transport in the Culebra. Because of this, SECOTP2D calculations need only be performed for the colloid carriers as indicated in Table 2; then, the effects of radioactive decay and daughter growth can be incorporated into the transport results by an appropriate application of the Bateman equations. ${ }^{46}$

The results $u D P, u D F, u C P$ and $u C F$ in Table 3 are the outcomes of the SECOTP2D calculations. For notational convenience, $u D P$ and $u D F$ are defined as being the release through $10,000 \mathrm{yr}$ (i.e., $\tau_{n T+1}$ ) for a unit release over the time interval $\left[\tau_{m}, \tau_{m+1}\right]$. Computationally, these results are obtained from the SECOTP2D calculations for a unit release over time interval $\left[\tau_{1}, \tau_{2}\right]$ and transport through time $\tau_{2}+\left(10,000-\tau_{m+1}\right)$. Experimental results indicate that microbial and mineral fragment colloids will undergo very little transport in the Culebra due to filtration effects. ${ }^{47,} 48$ Thus, the release of these colloids and their associated radionuclides to the 
accessible environment due to transport through the Culebra was assumed to be 0 in the 1996 WIPP PA (i.e., $u C P$ and $u C F$ in Table 3 were assumed to be 0 for these colloids, which resulted in radionuclides associated with microbial and mineral fragment colloids undergoing no transport). Actinide intrinsic colloids were found to exist in insignificant quantities and thus were not considered for transport in the Culebra. Humic colloids were found to transport similarly to dissolved radionuclides. ${ }^{48}$ As a result, humic colloids were not treated explicitly in the calculations (i.e., $f C E 0, f C E 1$ and $f C E 2$ in Table 7 of Ref. 12 were set to 0 for humic colloids, which resulted in radionuclides associated with humic colloids being transported in the same manner as dissolved radionuclides).

Due to the preceding simplifications, SECOTP2D results were only needed for dissolved radionuclides (i.e., calculations 1-8 in Table 2). For computational efficiency, these calculations were performed for partially and fully mined conditions, with all radionuclides (i.e., Am-241, Pu-239, U-234, Th-230) incorporated into each calculation. Thus, a total of 600 SECOTP2D calculations were actually performed (i.e., 300 for partially mined conditions and 300 for fully mined conditions). In each calculation, a $1 \mathrm{~kg}$ release of each radionuclide (i.e., Am-241, Pu-239, $\mathrm{U}-234$, Th-230) is assumed to take place between 0 and $50 \mathrm{yr}$ and then the transport of this release through 10,000 $\mathrm{yr}$ is calculated. For the unit release of U-234, the transport of both U-234 and its daughter Th-230 is modeled. In addition, the transport of a separate unit release of Th-230 is also modeled. This separation is needed to define $u D P$ and $u D F$ in Table 3 for U-234 and Th-230.

Once the transport results in Table 3 are available, the releases to the accessible environment for individual futures $\mathbf{x}_{s t}$ due to transport through the Culebra can be calculated as shown in Table 4, with this calculation also requiring the releases into the Culebra defined in Table 8 of Ref. 12.

\section{Transport in Culebra: Initial Results}

Of the 300 LHS elements under consideration, only element 33 of replicate R3 produced nonzero releases to the accessible environment, with releases only occurring for U-234 (Fig. 13). For all other sample elements and all radionuclides, no release to the accessible environment occurred for either partially or fully mined conditions.

\section{Transport in Culebra: CCDFs}

In concept, the CCDFs for radionuclide transport through the Culebra to the accessible environment can be constructed in the same manner as the CCDFs for cuttings (Fig. 6, Ref. 9), spallings (Fig. 16, Ref. 9), direct brine release (Fig. 16, Ref. 11), and release to the Culebra (Fig. 13, Ref. 12). The only difference is the use of $f_{S T}\left(\mathbf{x}_{S t}\right)$ in Table 4 for each sampled future rather than the total normalized release associated with one of the other release modes. 
For 299 of the LHS elements, the resulting CCDFs are degenerate (i.e., a probability of 0 of exceeding a normalized release of 0 ) because releases to the Culebra, if they occur, do not transport through to the accessible environment in the 10,000 yr period of interest. For element 33 of replicate R3, releases of U-234 to the Culebra have the potential to transport to the accessible environment (Fig. 13). However, no such releases to the Culebra occur, and so the resultant CCDF is again degenerate. Thus, all $300 \mathrm{CCDF}$ for transport through the Culebra to the accessible environment are degenerate.

\section{Transport in Culebra: Additional Results}

Due to the zero releases, the SECOTP2D results described in Sect. 10 do not provide suitable input for a sensitivity analysis. Therefore, to observe the effects of sampled (i.e., uncertain) variables on Culebra transport, SECOTP2D calculations were performed on a much smaller computational grid (Fig. 14) than the grid used to assess transport to the accessible environment (Fig. 5). In particular, transport was calculated across boundaries 3, 5, 7 and $10 \mathrm{~m}$ from the release point into the Culebra (Fig. 14) for U-234, which was selected for analysis because it is the least retarded of the radionuclides considered in the 1996 WIPP PA. Further, calculations were performed for the partially mined transmissivity fields calculated for replicate R1. The associated flow field calculated by SECOFL2D for each sample element is spatially variable. However, due to the small size of the computational grid in use (Fig. 14), a single constant velocity was interpolated from the spatially variable flow field for each sample element and used to define a spatially constant flow field. The calculations were performed for the 100 sample elements in replicate R1.

The releases (i.e., kilograms or fraction of initial release) over 10,000 yr across the four boundaries in Fig. 14 range from 0 to close to 1 (Fig. 15). Even at the small distances under consideration (i.e., 3, 5, 7, $10 \mathrm{~m}$ ), a significant number of the sample elements result in little transport across the boundaries.

There is significant uncertainty in the cumulative release curves in Fig. 15. One way to assess the sources of this uncertainty is by calculating partial rank correlation coefficients (PRCCs) between the cumulative releases and the relevant sampled variables (Table 5) with the PCCSRC program. ${ }^{49}$, 50 Due to their definitions and use within the analysis, significant correlations can potentially exist between CMTRXPOR, CMRTRDU, CVEL, CVELCF, CVELSC, CULCLIM and WOXSTAT. To eliminate the loss of information that results from the calculation of partial correlation coefficients in the presence of correlated variables, only CFRCSP, CMRTRDU and CVEL were used in the calculation of PRCCs.

As should be the case, release tends to increase as fluid velocity (CVEL) and fracture spacing (CFRCSP) increase and tends to decrease as matrix retardation (CMRTRDU) increases (Fig. 16), with CVEL, CFRCSP and CMRTRDU being the only variables with PRCCs that exceeded 0.5 in absolute value at some point in time. The positive effect for CFRCSP results because increasing CFRCSP decreases the surface area available for diffusion 
into the matrix and thus reduces radionuclide movement from the fractures into the surrounding matrix. The results in Fig. 16 are for transport across the boundary $10 \mathrm{~m}$ from the release point (Fig. 14). Essentially identical results were obtained for transport across the boundaries 3, 5 and $7 \mathrm{~m}$ from the release point (Fig. 12.5.3, Ref. 18).

The cumulative releases over 10,000 yr in Fig. 15 can also be summarized with box plots (Fig. 17). For most sample elements, these releases are small. The median values for 3 and $5 \mathrm{~m}$ are approximately 0.06 and 0.0006 , and the median values for 7 and $10 \mathrm{~m}$ are less than $1 \times 10^{-5}$. The means are between 0.1 and 0.4 and are dominated by the few largest values. The rapid attenuation indicated in Figs. 15 and 17 is why there is little radionuclide transport in the Culebra to the boundary with the accessible environment within the $10,000 \mathrm{yr}$ period under consideration.

Stepwise regression analysis with the STEPWISE program ${ }^{51,52}$ and rank-transformed data ${ }^{53}$ can also be used to investigate the uncertainty in radionuclide transport (Table 6). In the stepwise regression analyses summarized in Table 6, a variable was required to have an $\alpha$-value of 0.02 to enter a regression model and an $\alpha$-value of 0.05 to be retained in a regression model.

As shown by the stepwise regressions in Table 6, the two dominant variables for U-234 transport over 10,000 yr are CMRTRDU and CVEL, with transport tending to decrease as CMRTRDU increases and tending to increase as CVEL increases. These same patterns were also observed in the analysis with PRCCs (Fig. 16). Lesser effects are indicated for CFRCSP and WOXSTAT. The small positive effect for CFRCSP results from increasing the surface area available for diffusion into the matrix. The positive effect for WOXSTAT results from its role in determining the distribution coefficients for use in the definition of CMRTRDU (Table 5). In particular, smaller distribution coefficients are associated with WOXSTAT $=1$; in turn, this results in smaller values for CMRTRDU and hence the positive effect for WOXSTAT in Table 6. The use of WOXSTAT in the definition of CMRTRDU results in a rank correlation of -0.8661 between WOXSTAT and CMRTRDU, which is the cause of the instability in the regression coefficients for WOXSTAT and CMRTRDU in Table 6.

Additional perspective is provided by the scatterplots in Fig. 18 for U-234 transport across the 3 and $10 \mathrm{~m}$ boundaries in Fig. 14. The tendency of the release to decrease with increasing values for CMRTRDU is clearly evident. The division of CMRTRDU into a range of values below $10^{3}$ and a range of values above $10^{4}$ is due to WOXSTAT (see CMRTRDU in Table 5), with the smaller values corresponding to the use of CMKDU6 to define CMRTRDU (i.e., WOXSTAT $=1$ ) and the larger values corresponding to the use of CMKDU4 to define CMRTRDU (i.e., WOXSTAT $=0$ ). The larger values for CMRTRDU (i.e., WOXSTAT $=0$, which implies use of $C M K D U 4$ ) result in almost no transport across the $10 \mathrm{~m}$ boundary. The positive effect of $C V E L$ on transport is evident but less strong than the negative effect of CMRTRDU. 


\section{Discussion}

At a conceptual level, radionuclide transport in the Culebra Dolomite was treated in the same manner as direct releases to the accessible environment. Thus, the general comments made in the discussion for the direct releases also apply to radionuclide transport in the Culebra. 9,11

The most important aspect of radionuclide transport in the Culebra in the 1996 WIPP PA was that there was no transport to the accessible environment over the $10,000 \mathrm{yr}$ period specified by the EPA for assessing compliance with 40 CFR 191. In particular, a $1 \mathrm{~kg}$ release to the Culebra over the repository of any of the four radionuclides considered in the transport calculations (i.e., ${ }^{241} \mathrm{Am},{ }^{239} \mathrm{Th},{ }^{234} \mathrm{U},{ }^{230} \mathrm{Th}$ ) resulted in no transport to the boundary with the accessible environment over 10,000 yr. Actually, one of the 300 LHS elements did produce a release of

${ }^{234} \mathrm{U}$ to the accessible environment, but this particular sample element had no ${ }^{234} \mathrm{U}$ release to the Culebra and so the corresponding $\mathrm{CCDF}$ for release to the accessible environment due to transport through the Culebra was degenerate (i.e., had a probability of zero of exceeding a release of zero). Thus, even in the presence of substantial subjective uncertainty, the 1996 WIPP PA indicates that the Culebra does not constitute a viable transport route to the accessible environment.

In addition, the releases to the Culebra were sufficiently small that they would not result in noncompliance with 40 CFR 191 even if they were transported through the Culebra to the accessible environment. ${ }^{12}$ Specifically, most CCDFs for release into the Culebra are to the left of the boundary specified in 40 CFR 191 (Figs. 13, 14, Ref. 12). Thus, even in the absence of the extensive retardation in the Culebra predicted as part of the 1996 WIPP PA, the observed releases into the Culebra would not have resulted in noncompliance with 40 CFR 191, although a few of the CCDFs would have crossed the boundary line given a complete absence of physical and chemical retardation.

A variety of transport assumptions for the Culebra have been considered in past PAs for the WIPP, with many of these assumptions and their associated parameters resulting in the potential for substantial radionuclide transport in the Culebra. ${ }^{55-57}$ However, the refinement of the Culebra transport model through time, the development of an appropriate set of model parameters, and an assessment of the subjective uncertainty in these parameters is leading to the conclusion that the Culebra does not constitute a significant pathway to the accessible environment at the WIPP.

The construction of CCDFs for radionuclide transport through the Culebra has the potential to become computationally prohibitive unless the overall calculation is planned carefully. The radionuclide transport equations solved by SECOTP2D are linear with respect to radionuclide release rate into the Culebra. This linearity provided a way to efficiently calculate radionuclide transport in the Culebra by performing calculations with SECOTP2D for unit releases into the Culebra, saving appropriate time-dependent results from these calculations, and then using these time-dependent results to algebraically construct transport results for arbitrary time-dependent releases into the Culebra. In the end, this procedure was not used because there was no transport through the Culebra to the 
accessible environment. However, if this had not been the case, then this procedure would have been essential to the successful application of the Monte Carlo procedure in use for the construction of CCDFs arising from stochastic uncertainty for radionuclide transport in the Culebra to the accessible environment.

As there was no long-term transport to the accessible environment in the Culebra, nor in the Dewey Lake Reds, the anhydrite marker beds, the borehole or the shaft (Sect. 10, Ref. 12), release to the accessible environment, and hence compliance with 40 CFR 191, was dominated by the direct releases (i.e., cuttings, cavings, spallings, direct brine release) in the 1996 WIPP PA. $9,11,13$

\section{Acknowledgment}

Work performed for Sandia National Laboratories (SNL), which is a multiprogram laboratory operated by Sandia Corporation, a Lockheed Martin Company, for the United States Department of Energy under contract DE-AC04-94AL85000. Review provided at SNL by M. Chavez, C. Crawford and M.S. Tierney. Editorial support provided by L. Harrison, T. Allen and H. Olmstead of Tech Reps, Inc.

1. U.S. Environmental Protection Agency, 40 CFR Part 191: Environmental Standards for the Management and Disposal of Spent Nuclear Fuel, High-Level and Transuranic Radioactive Wastes; Final Rule, Federal Register, 1985, 50(182), 38066-38089.

2. U.S. Environmental Protection Agency, 40 CFR Part 191: Environmental Radiation Protection Standards for the Management and Disposal of Spent Nuclear Fuel, High-Level and Transuranic Radioactive Wastes; Final Rule, Federal Register, 1993, 58(242), 66398-66416.

3. U.S. Environmental Protection Agency, 40 CFR Part 194: Criteria for the Certification and Re-Certification of the Waste Isolation Pilot Plant's Compliance With the 40 CFR Part 191 Disposal Regulations; Final Rule, Federal Register, 1996, 61(28), 5224-5245.

4. Howard, B.A., Crawford, M.B., Galson, D.A., \& Marietta, M.G., Regulatory Basis for the Waste Isolation Pilot Plant Performance Assessment, Reliability Engineering and System Safety (in this issue).

5. U.S. Department of Energy, Title 40 CFR Part 191 Compliance Certification Application for the Waste Isolation Pilot Plant, DOE/CAO-1996-2184, Volumes I-XXI, U.S. Department of Energy, Carlsbad Area Office, Carlsbad, NM, 1996.

6. Helton, J.C., Anderson, D.R., Basabilvazo, G., Jow, H.-N., \& Marietta, M.G., Conceptual Structure of the 1996 Performance Assessment for the Waste Isolation Pilot Plant, Reliability Engineering and System Safety (in this issue).

7. Helton, J.C., Davis, F.J., \& Johnson, J.D., Characterization of Stochastic Uncertainty in the 1996 Performance Assessment for the Waste Isolation Pilot Plant, Reliability Engineering and System Safety (in this issue). 
8. Helton, J.C., Martell, M.-A., \& Tierney, M.S., Characterization of Subjective Uncertainty in the 1996 Performance Assessment for the Waste Isolation Pilot Plant, Reliability Engineering and System Safety (in this issue).

9. Berglund, J.W., Garner, J.W., Helton, J.C., Johnson, J.D., \& Smith, L.N., Direct Releases to the Surface and Associated Complementary Cumulative Distribution Functions in the 1996 Performance Assessment for the Waste Isolation Pilot Plant: Cuttings, Cavings and Spallings, Reliability Engineering and System Safety (in this issue).

10. Vaughn, P., Bean, J.E., Helton, J.C., Lord, M.E., MacKinnon, R.J., \& Schreiber, J.D., Representation of TwoPhase Flow in the Vicinity of the Repository in the 1996 Performance Assessment for the Waste Isolation Pilot Plant, Reliability Engineering and System Safety (in this issue).

11. Stoelzel, D.M., O'Brien, D.G., Garner, J.W., Helton, J.C., Johnson, J.D., \& Smith, L.N., Direct Releases to the Surface and Associated Complementary Cumulative Distribution Functions in the 1996 Performance Assessment for the Waste Isolation Pilot Plant: Direct Brine Release, Reliability Engineering and System Safety (in this issue).

12. Stockman, C.T., Garner, J.W., Helton, J.C., Johnson, J.D., Shinta, A., \& Smith, L.N., Radionuclide Transport in the Vicinity of the Repository and Associated Complementary Cumulative Distribution Functions in the 1996 Performance Assessment for the Waste Isolation Pilot Plant, Reliability Engineering and System Safety (in this issue).

13. Helton, J.C., Anderson, D.R., Basabilvazo, G., Jow, H.-N., \& Marietta, M.G., Summary Discussion of the 1996 Performance Assessment for the Waste Isolation Pilot Plant, Reliability Engineering and System Safety (in this issue).

14. McKay, M.D., Beckman, R.J., \& Conover, W.J., A Comparison of Three Methods for Selecting Values of Input Variables in the Analysis of Output from a Computer Code, Technometrics, 1979, 21(2), 239-245.

15. Helton, J.C, Uncertainty and Sensitivity Analysis Techniques for Use in Performance Assessment for Radioactive Waste Disposal, Reliability Engineering and System Safety, 1993, 42(2-3), 327-367.

16. Helton, J.C., Bean, J.E., Economy, K., Garner, J.W., MacKinnon, R.J., Miller, J., Schreiber, J.D., \& Vaughn, P., Uncertainty and Sensitivity Analysis for Two-Phase Flow in the Vicinity of the Repository in the 1996 Performance Assessment for the Waste Isolation Pilot Plant: Undisturbed Conditions, Reliability Engineering and System Safety (in this issue).

17. Helton, J.C., Bean, J.E., Economy, K., Garner, J.W., MacKinnon, R.J., Miller, J., Schreiber, J.D., \& Vaughn, P., Uncertainty and Sensitivity Analysis for Two-Phase Flow in the Vicinity of the Repository in the 1996 Performance Assessment for the Waste Isolation Pilot Plant: Disturbed Conditions, Reliability Engineering and System Safety (in this issue).

18. Helton, J.C., Bean, J.E., Berglund, J.W., Davis, F.J., Economy, K., Garner, J.W., Johnson, J.D., MacKinnon, R.J., Miller, J., O'Brien, D.G., Ramsey, J.L., Schreiber, J.D., Shinta, A., Smith, L.N., Stoelzel, D.M., Stockman, C., \& Vaughn, P., Uncertainty and Sensitivity Analysis Results Obtained in the 1996 Performance Assessment for the Waste Isolation Pilot Plant, SAND98-0365, Sandia National Laboratories, Albuquerque, NM, 1998. 
19. Meigs, L. \& McCord, J., Physical Transport in the Culebra Dolomite, Sandia WIPP Central Files (SWCF) WPO\#39167 (part of WPO\#37450), Sandia National Laboratories, Albuquerque, NM, 1996.

20. LaVenue, A.M., Analysis of the Generation of Transmissivity Fields for the Culebra Dolomite. SWCF WPO \# 40517, Sandia National Laboratories, Albuquerque, NM, 1996.

21. Wallace, M.G., Record of FEP Screening Work FEP ID\# NS-11, Subsidence Associated with Mining Inside or Outside of the Controlled Area. SWCF WPO \# 40816, Sandia National Laboratories, Albuquerque, NM, 1996.

22. Corbet, T. \& Swift, P., Distribution for Non-Salado Parameter for SECOFL2D: Climate Index. Memo to M.S. Tierney, April 12, 1996. SWCF WPO \# 37465, Sandia National Laboratories, Albuquerque, NM, 1996.

23. Corbet, T. \& Swift, P., Parameters Required for SECOFL2D: Climate Index. SWCF WPO \# 36425, Sandia National Laboratories, Albuquerque, NM, 1996.

24. Hunter, R.L., A Regional Water Balance for the Waste Isolation Pilot Plant (WIPP) Site and Surrounding Area, SAND84-2233, Sandia National Laboratories, Albuquerque, NM, 1985.

25. Robinson, T.W. \& Lang, W.B., Geology and Ground-Water Conditions of the Pecos River Valley in the Vicinity of Laguna Grande de la Sal, New Mexico, with Special Reference to the Salt Content of the River Water, Twelfth and Thirteenth Biennial Reports of the State Engineer of New Mexico for the 23rd, 24th, 25th, and 26th Fiscal Years, July 1, 1934 to July 30, 1938, State Engineer, Santa Fe, NM, 1938. SWCF WPO\#37942.

26. Mercer, J.W., Geohydrology of the Proposed Waste Isolation Pilot Plant Site, Los Medaños Area, Southeastern New Mexico, U.S. Geological Survey, Water-Resources Investigations Report 83-4016, Prepared in cooperation with the U.S. Department of Energy, Albuquerque, NM, 1983.

27. McDonald, M.G. \& Harbaugh, A.W., A Modular Three-Dimensional Finite-Difference Ground-Water Flow Model, Techniques of Water-Resources Investigations of the United States Geological Survey, Book 6, Modeling Techniques, U.S. Geological Survey, Denver, CO.", 1988.

28. Roache, P.J., Computational Fluid Dynamics, Revised Edition, Hermosa Publishers, Albuquerque, NM, 1976.

29. Dendy, J.E. Jr., McCormick, S.F., Ruge, J.W., Russell, T.F., \& Schaffer, S., Multigrid Methods for ThreeDimensional Petroleum Reservoir Simulation. Paper presented at the Proc. IOth Symposium on Reservoir Simulation, SPE 18409, 6-8 Feb. 1989, Houston, TX, Society of Petroleum Engineers, Richardson, TX, pp. 19-25.

30. Dendy, J.E. Jr., Ida, M.P., \& Rutledge, J.M., A Semicoarsening Multigrid Algorithm for SIMD Machines, SIAM Journal on Scientific and Statistical Computing, 1992, 13(6), 1460-1469.

31. Roache, P.J., Blaine, R.L., \& Baker, B.L., SECOFL2D User's Manual Version 3.03, SWCF WPO \# 37271, Sandia National Laboratories, Albuquerque, NM, 1996.

32. Ramsey, J. \& Wallace, M.G., Analysis Package for the Culebra Flow and Transport Calculations (Task 3) of the Performance Assessment Analyses Supporting the Compliance Certification Application, SWCF WPO\#40516, Sandia National Laboratories, Albuquerque, NM, 1996. 
33. WIPP PA (Performance Assessment), WIPP PA User's Manual for SECOTP2D, Version 1.41, SWCF WPO \# 45734, Sandia National Laboratories, Albuquerque, NM, 1997.

34. Meigs, L. \& McCord, J., Non-Salado: Advective Porosity for the Culebra Dolomite (WPO \# 37227). Memo to J. Ramsey, June 6, 1996. SWCF WPO \# 38939, Sandia National Laboratories, Albuquerque, NM, 1996.

35. Bear, J., Dynamics of Fluids in Porous Media, Dover Publications, New York, NY, 1972.

36. McCord, J., Longitudinal Dispersivity for the Culebra Dolomite, SWCF WPO\#37230, Sandia National Laboratories, Albuquerque, NM, 1996.

37. Brush, L.H., Revised Free-Solution Tracer Diffusion Coefficients $\left(\mathrm{D}_{\mathrm{sol}} \mathrm{S}\right)$ for Dissolved $\mathrm{Pu}, \mathrm{Am}, \mathrm{U}, \mathrm{Th}, \mathrm{Np}, \mathrm{Cm}$ and $\mathrm{Ra}$ in Boreholes and Culebra for Use in PA Calculations to Support the WIPP CCA, Laboratory Column Experiments for Radionuclide Adsorption Studies of the Culebra Dolomite Member of the Rustler Formation, D.A. Lucero, G.O. Brown, and C.E. Heath, SAND97-1763, Sandia National Laboratories, Albuquerque, NM, 1998, D-4 through D-8.

38. Wallace, M.G., Distribution of Non-Salado Parameter for SECOTP2D: Fracture Tortuosity. Memo to M. Tierney, May 2, 1996. SWCF WPO \# 39365, Sandia National Laboratories, Albuquerque, NM, 1996.

39. Brush, L.H. \& Storz, L.J., Revised Ranges and Probability Distributions of $\mathrm{K}_{\mathrm{d}} \mathrm{s}$ for Dissolved Pu, Am, U, Th, and $\mathrm{Np}$ in Culebra for the PA Calculations to Support the WIPP CCA. Memo to M.S. Tierney, July 24, 1996. SWCF WPO \# 41561, Sandia National Laboratories, Albuquerque, NM, 1996.

40. Meigs, L., Non-Salado: Diffusive Tortuosity for the Culebra Dolomite (WPO \# 37226). Memo to J. Ramsey, May 16, 1996. SWCF WPO \# 38940, Sandia National Laboratories, Albuquerque, NM, 1996.

41. Martell, M.-A., Additional Information for the Culebra Transport Parameter Id: 843 idpram: DNSGRAIN, idmtrl: CULEBRA, WIPP Data Entry Form 464 at WPO \# 32689. Memo to C. Lattier, December 10, 1996. SWCF WPO \# 32689, Sandia National Laboratories, Albuquerque, NM, 1996.

42. Fletcher, C.A.J., Computational Techniques for Fluid Dynamics, Vol. I and II, 2nd edn., Springer-Verlag, NY, 1988.

43. Sweby, P.K., High Resolution Schemes Using Flux Limiters for Hyperbolic Conservation Laws, SIAM Journal on Numerical Analysis, 1984, 21(5), 995-1011.

44. Huyakorn, P.S., Lester, B.H., \& Mercer, J.W., An Efficient Finite Element Technique for Modelling Transport in Fractured Porous Media: Single Species Transport, Water Resources Research, 1983, 19(3), 841-854.

45. Roache, P.J., The SECO Suite of Codes for Site Performance Assessment. In High Level Radioactive Waste Management, Proceedings of the Fourth Annual International Conference. Las Vegas, NV, April 26-30, 1993. American Nuclear Society, La Grange Park, IL, 1993, 2, 1586-1594.

46. Bateman, H., The Solution of a System of Differential Equations Occurring in the Theory of Radioactive Transformations, Proceedings of the Cambridge Philosophical Society, 1910, 15(5), 423-427. 
47. Lucero, D.A., Behl, Y.K., Brown, G.O., Budge, K.G., Dunn, M., Gillow, J.B., Francis, A.J., \& Papenguth, H.W., Laboratory Evaluation of Colloid Transport under Simulated Subsurface Conditions at the Waste Isolation Pilot Plant (WIPP): 2. Large-Scale-Intact-Core Column Flow Experiments, in D.T. Reed, S. Clark, and L. Rao (eds.), Experimental and Modeling Studies of Radionuclide Speciation in Real Systems, Plenum Publishing Corp., New York, 1996. SAND96-2741J, SWCF WPO \#42864, Sandia National Laboratories, Albuquerque, NM, 1996.

48. Papenguth, H.W., Development of Parameter Values Describing Colloidal Actinide Retardation in the Culebra Dolomite, in Attachment A, Parameter Record Package WPO \# 38173: Colloidal Actinide Retardation Parameters, Sandia National Laboratories, Albuquerque, NM, 1996.

49. Iman, R.L., Shortencarier, M.J., \& Johnson, J.D., A FORTRAN 77 Program and User's Guide for the Calculation of Partial Correlation and Standardized Regression Coefficients, NUREG/CR-4122, SAND85-0044, Sandia National Laboratories, Albuquerque, NM, 1985.

50. WIPP PA (Performance Assessment), PCCSRC, Version 2.21, User's Manual, Document Version 1.0, SWCF WPO \#27773, Sandia National Laboratories, Albuquerque, NM, 1995.

51. Iman, R.L., Davenport, J.M., Frost, E.L., \& Shortencarier, M.J., Stepwise Regression with PRESS and Rank Regression (Program and User's Guide), SAND79-1472, Sandia National Laboratories, Albuquerque, NM, 1980.

52. WIPP PA (Performance Assessment), STEPWISE, Version 2.20, User's Manual, Document Version 1, Sandia WIPP Central Files WPO \#27768, Sandia National Laboratories, Albuquerque, NM, 1995.

53. Iman, R.L., \& Conover, W.J., The Use of the Rank Transform in Regression, Technometrics, 1979, 21(4), 499-509.

54. Helton, J.C., Garner, J.W., Marietta, M.G., Rechard, R.P., Rudeen, D.K., \& Swift, P.N., Uncertainty and Sensitivity Analysis Results Obtained in a Preliminary Performance Assessment for the Waste Isolation Pilot Plant, Nuclear Science and Engineering, 1993, 114(4), 286-331.

55. Helton, J.C., Anderson, D.R., Baker, B.L., Bean, J.E., Berglund, J.W., Beyeler, W., Garner, J.W., Iuzzolino, H.J., Marietta, M.G., Rechard, R.P., Roache, P.J., Rudeen, D.K., Schreiber, J.D., Swift, P.N., Tierney, M.S., \& Vaughn, P., Effect of Alternative Conceptual Models in a Preliminary Performance Assessment for the Waste Isolation Pilot Plant, Nuclear Engineering and Design, 1995, 154(3), 251-344.

56. Helton, J.C., Anderson, D.R., Baker, B.L., Bean, J.E., Berglund, J.W., Beyeler, W., Economy, K., Garner, J.W., Hora, S.C., Iuzzolino, H.J., Knupp, P., Marietta, M.G., Rath, J., Rechard, R.P., Roach, P.J., Rudeen, D.K., Salari, K., Schreiber, J.D., Swift, P.N., Tierney, M.S., and Vaughn, P., Uncertainty and Sensitivity Analysis Results Obtained in the 1992 Performance Assessment for the Waste Isolation Pilot Plant, Reliability Engineering and System Safety, 1996, 51(1), 53-100. 
Figure Captions

Fig. 1. Extent of impacted area in the Culebra Dolomite from mining in the McNutt potash zone outside the land withdrawal boundary (Ref. 21).

Fig. 2. Extent of impacted area in the Culebra Dolomite from mining in the McNutt potash zone inside and outside the land withdrawal boundary (Ref. 21).

Fig. 3. Regional and local domains used in representation of groundwater flow in the Culebra Dolomite.

Fig. 4. Regional model domain spatial discretization and type of boundary conditions for groundwater flow in the Culebra Dolomite.

Fig. 5. Local domain spatial discretization for groundwater flow in the Culebra Dolomite.

Fig. 6. Constant boundary values (m) specified for $h$ on lower boundary in Fig. 4 for use in solution of Eq. (6) (Ref. 20).

Fig. 7. Parallel plate dual porosity conceptualization.

Fig. 8. Illustration of stretched grid used for discretization of matrix (i.e., diffusive) domain into points $z_{i}$, with points close together at the fracture-matrix interface and farther apart at greater distances from this interface.

Fig. 9. Schematic of finite volume staggered mesh showing internal and ghost cells. Concentrations, C, are defined at cell centers and velocities, $\mathbf{v}=[u, v]$, at cell faces (Fig. 2, Ref. 33).

Fig. 10. Velocity field calculated by SECOFL2D for sample element 40 in replicate 1 for unmined, partially mined and fully mined conditions.

Fig. 11. Travel paths for nonreactive, nonsorbing particle released at center of repository for different values of $\mathbf{v}(x, y)$ for unmined, partially mined and fully mined conditions.

Fig. 12. Travel times to accessible environment for nonreactive, nonsorbing particles released at center of repository for different values of velocity fietd $\mathbf{v}(x, y)$ for unmined, partially mined and fully mined conditions for 100 sample elements in replicate R1. These travel times should not be interpreted as being representative of actual radionuclide transport times (see text).

Fig. 13. Cumulative transport to accessible environment under partially mined and fully mined conditions for LHS element 33 of replicate $\mathrm{R} 3$ for unit release $(1 \mathrm{~kg})$ of $\mathrm{U}-234$ to the Culebra over the time interval [0,50 yr].

Fig. 14. Computational grid used in sensitivity analysis of SECOTP2D results.

Fig. 15. Cumulative U-234 releases to the 3, 5, 7 and $10 \mathrm{~m}$ boundaries in Fig. 14 for $1 \mathrm{~kg}$ release over time interval $[0,50 \mathrm{yr}]$.

Fig. 16. Partial rank correlation coefficients (PRCCs) for cumulative U-234 releases across boundary $10 \mathrm{~m}$ from release point into Culebra Dolomite for $1 \mathrm{~kg}$ release over time interval [0,50 yr].

Fig. 17. Boxplot for cumulative transport over $10,000 \mathrm{yr}$ of U-234 across the 3,5, 7 and $10 \mathrm{~m}$ boundaries in Fig. 14 for a $1 \mathrm{~kg}$ release over the time interval [0,50 yr] (see Sect. 2, Ref. 16, for a discussion of boxplots).

Fig. 18. Scatterplots for cumulative transport over $10,000 \mathrm{yr}$ of $U-234$ across the 3 and $10 \mathrm{~m}$ boundaries in Fig. 14 for $1 \mathrm{~kg}$ release over time interval [0,50 yr] versus CMRTRDU and CVEL. 


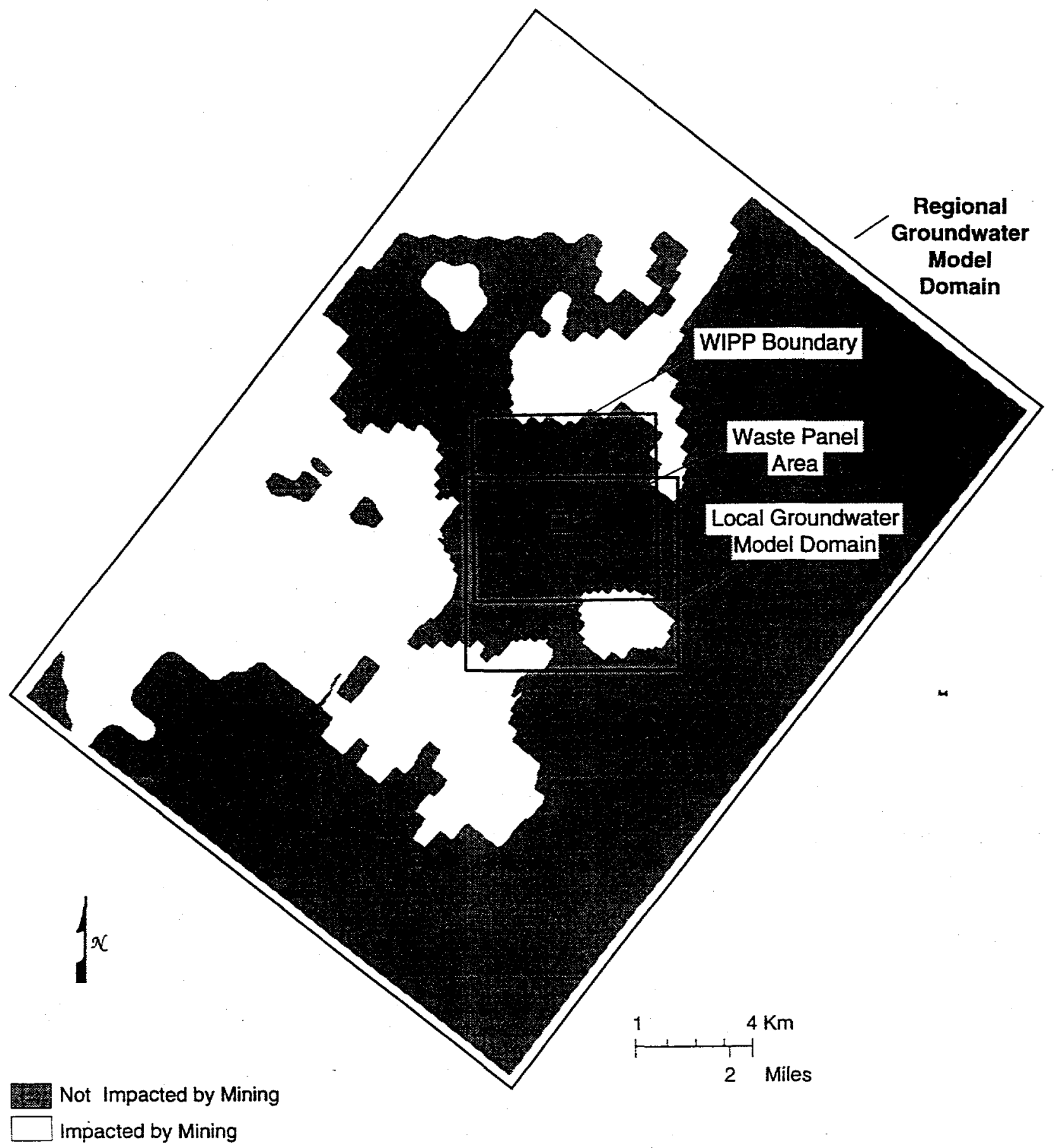

TRI-61 15-402-0

Fig. 1. Extent of impacted area in the Culebra Dolomite from mining in the McNutt potash zone outside the land withdrawal boundary (Ref. 21). 


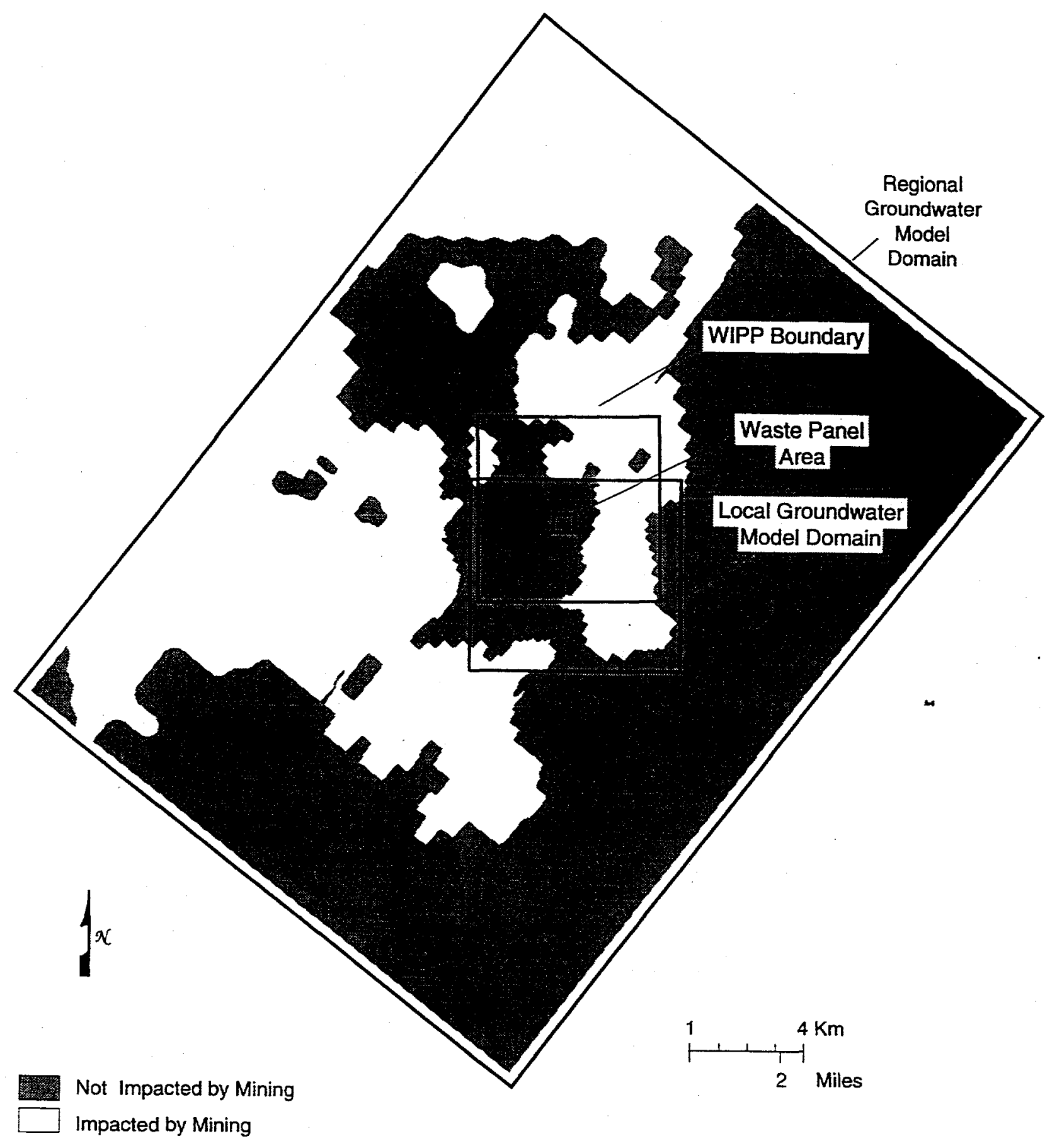

TRI-6115-401-0

Fig. 2. Extent of impacted area in the Culebra Dolomite from mining in the McNutt potash zone inside and outside the land withdrawal boundary (Ref. 21). 


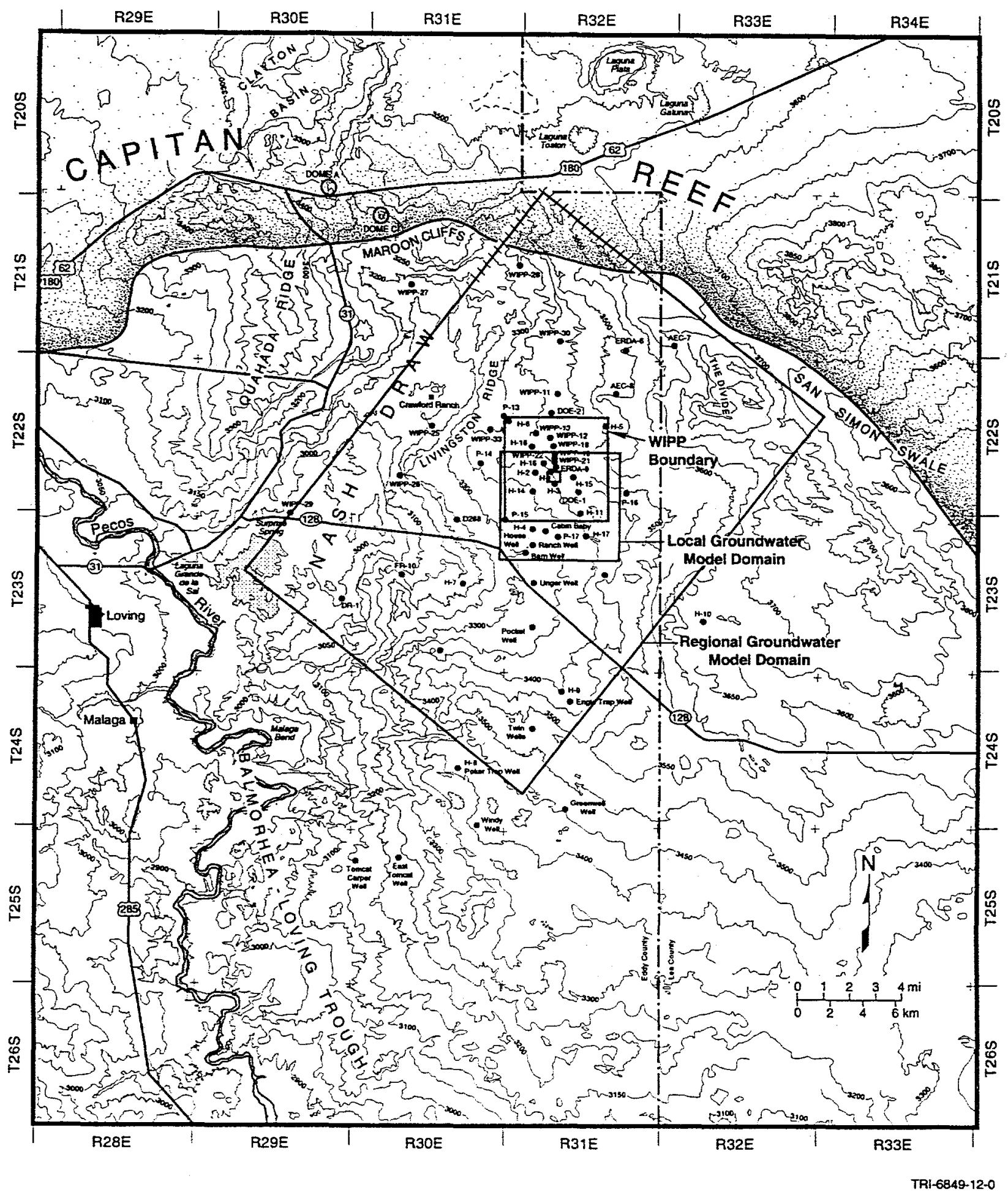

Fig. 3. Regional and local domains used in representation of groundwater flow in the Culebra Dolomite. 


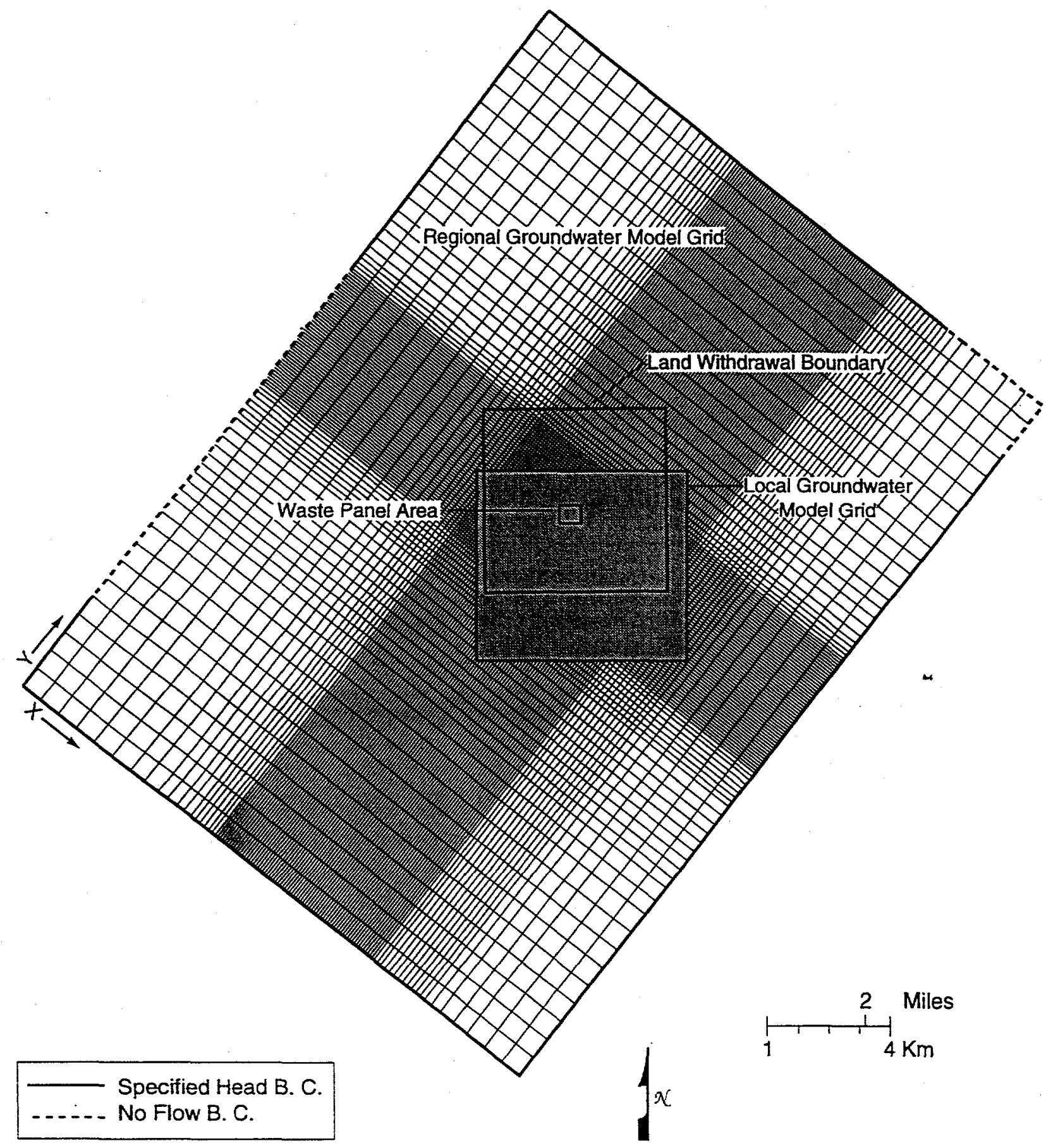

TR!-6849-9-1

Fig. 4. Regional model domain spatial discretization and type of boundary conditions for groundwater flow in the Culebra Dolomite. 


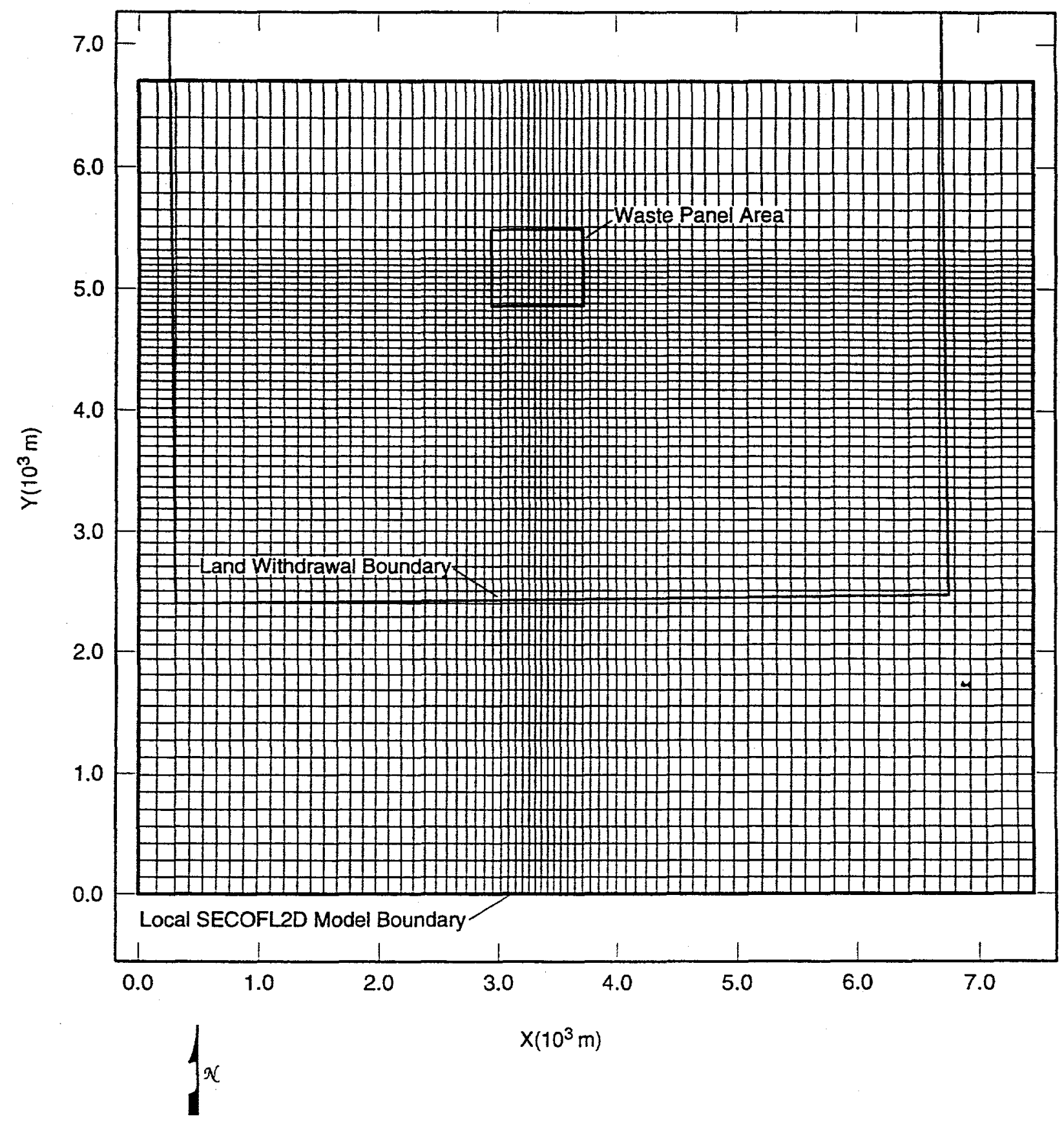

TRI-6849-7-20UP

Fig. 5. Local domain spatial discretization for groundwater flow in the Culebra Dolomite. 


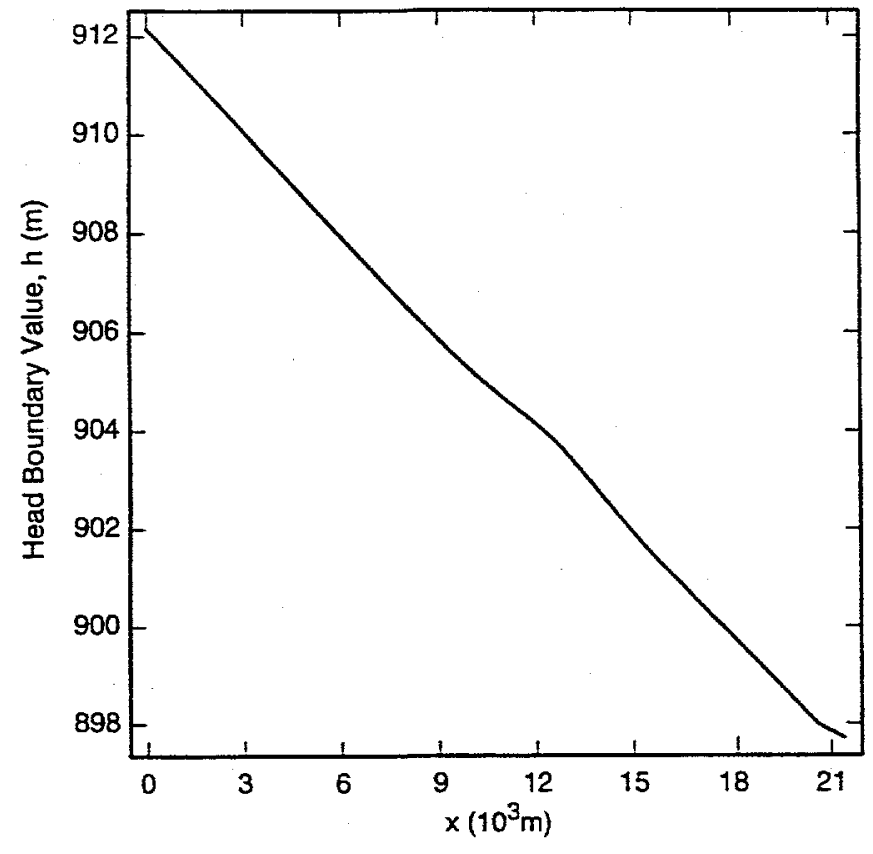

TRi-6342-5246-0

Fig. 6. Constant boundary values (m) specified for $h$ on lower boundary in Fig. 4 for use in solution of Eq. (6) (Ref. 20).

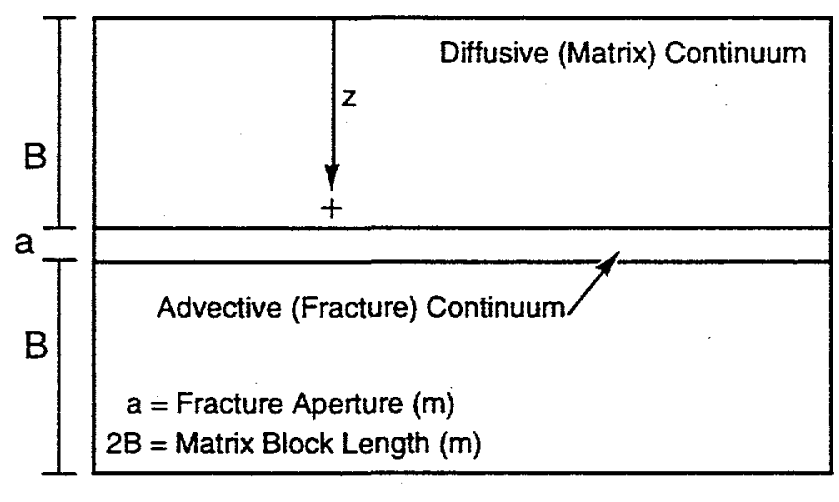

TनI-6342-5245-1

Fig. 7. Parallel plate dual porosity conceptualization.

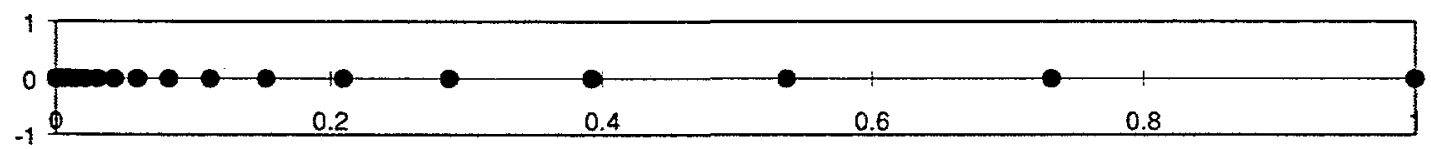

Fig. 8. Illustration of stretched grid used for discretization of matrix (i.e., diffusive) domain into points $z_{i}$, with points close together at the fracture-matrix interface and farther apart at greater distances from this interface. 


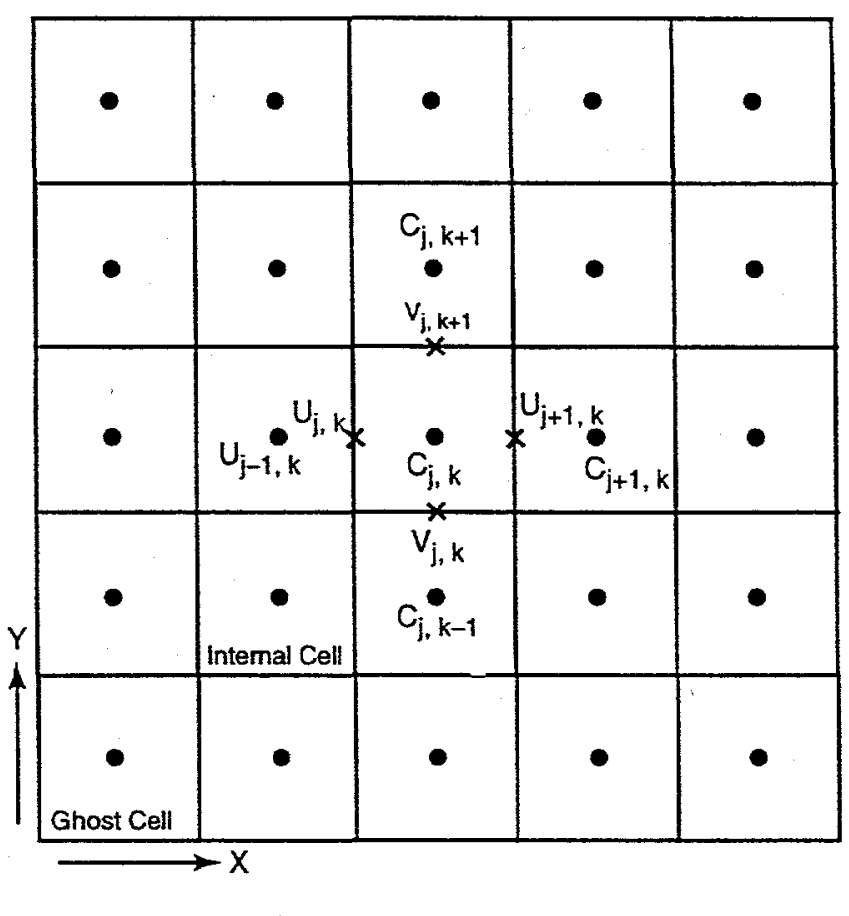

TRI.6342.57090

Fig. 9. Schematic of finite volume staggered mesh showing internal and ghost cells. Concentrations, $C$, are defined at cell centers and velocities, $\mathbf{v}=[u, v]$, at cell faces (Fig. 2, Ref. 33 . 

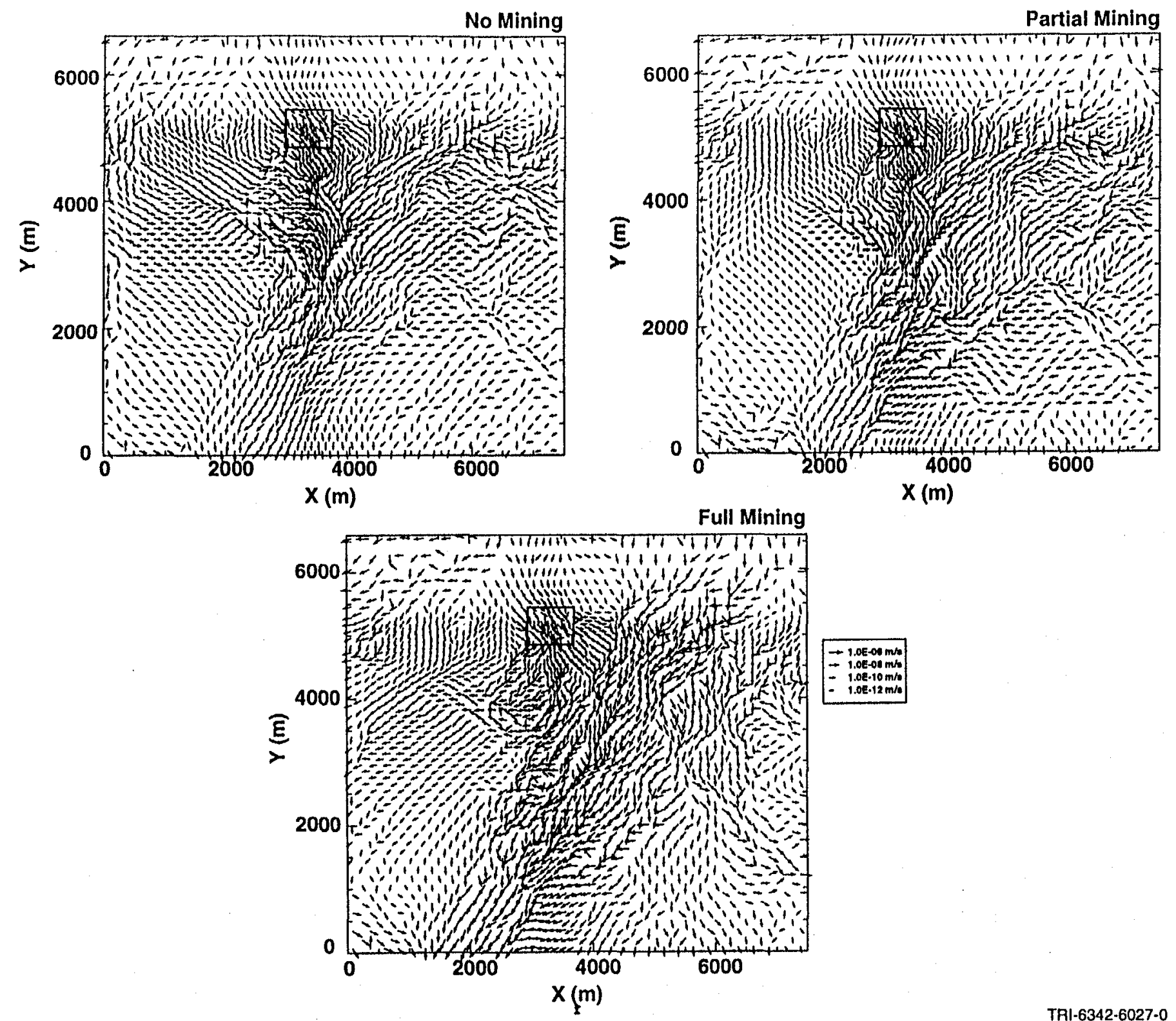

TRI-6342-6027-0

Figure 10. Velocity ficld calculated by SECOFL2D for sample clement $40 \mathrm{in} \mathrm{replicate} 1$ for unmined, partially mined and fully mined conditions. 

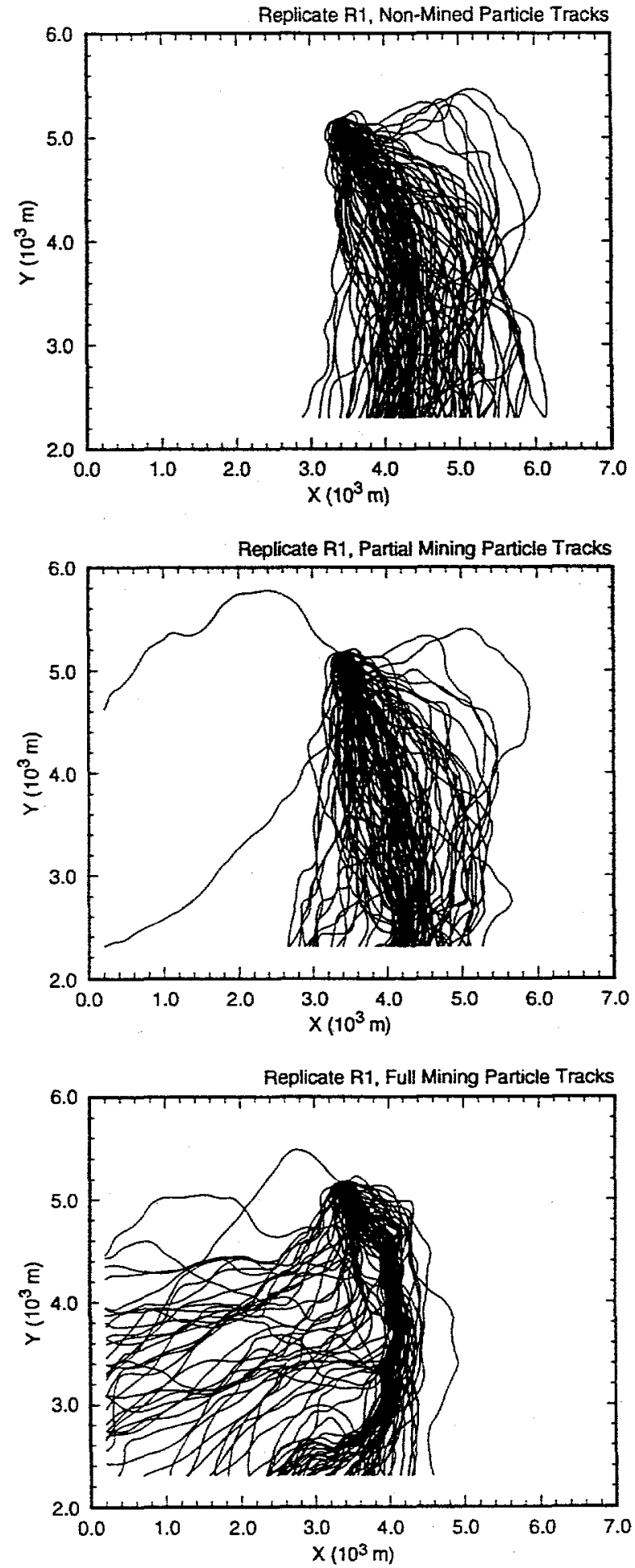

TRI-6342-5133-0

Fig. 11. Travel paths for nonreactive, nonsorbing particle released at center of repository for different values of $\mathbf{v}(x, y)$ for unmined, partially mined and fully mined conditions. 


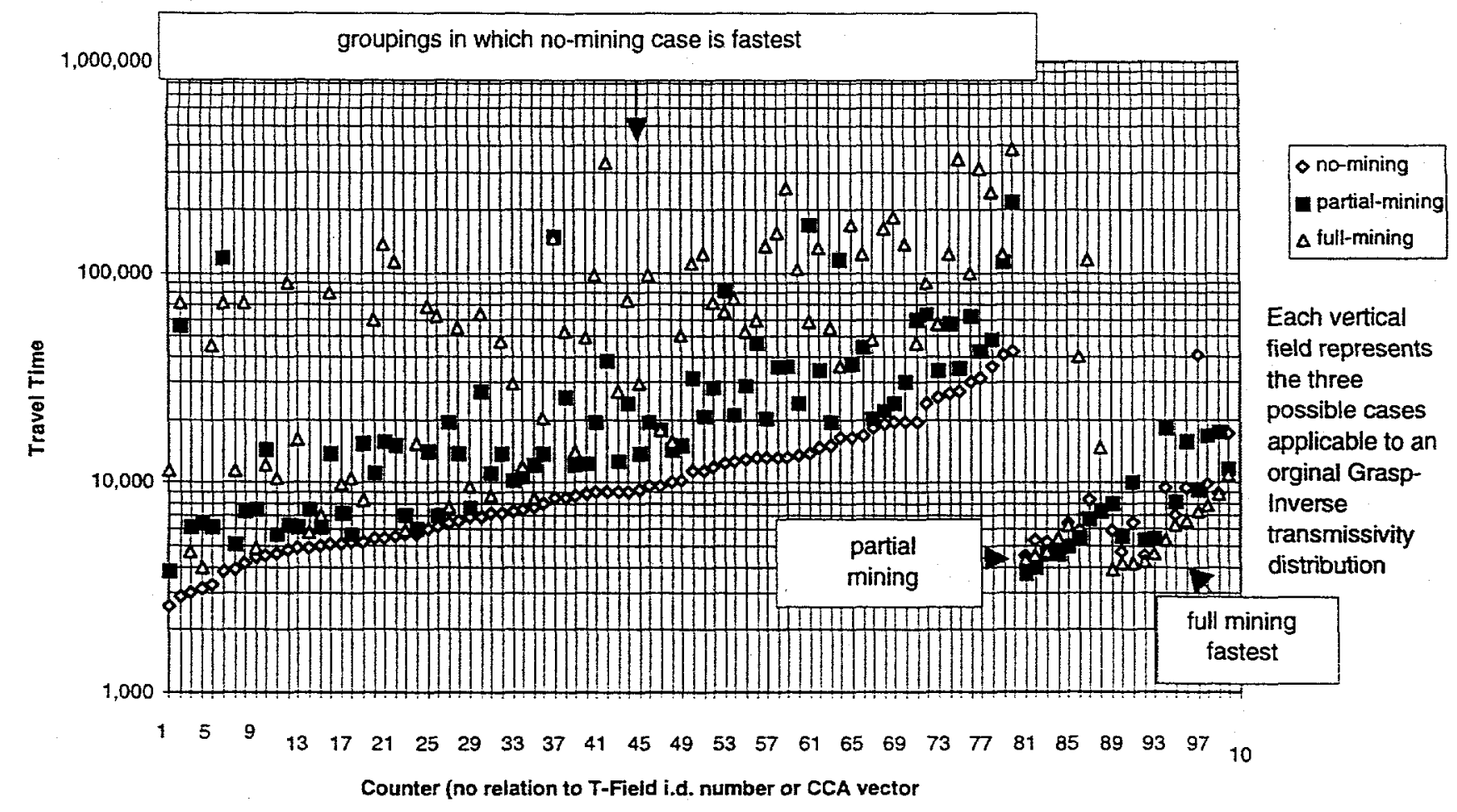

Fig. 12. Travel times to accessible environment for nonreactive, nonsorbing particles released at center of repository for different values of velocity field $\mathbf{V}(x, y)$ for unmined, partially mined and fully mined conditions for 100 sample elements in replicate R1. These travel times should not be interpreted as being representative of actual radionuclide transport times (see text).

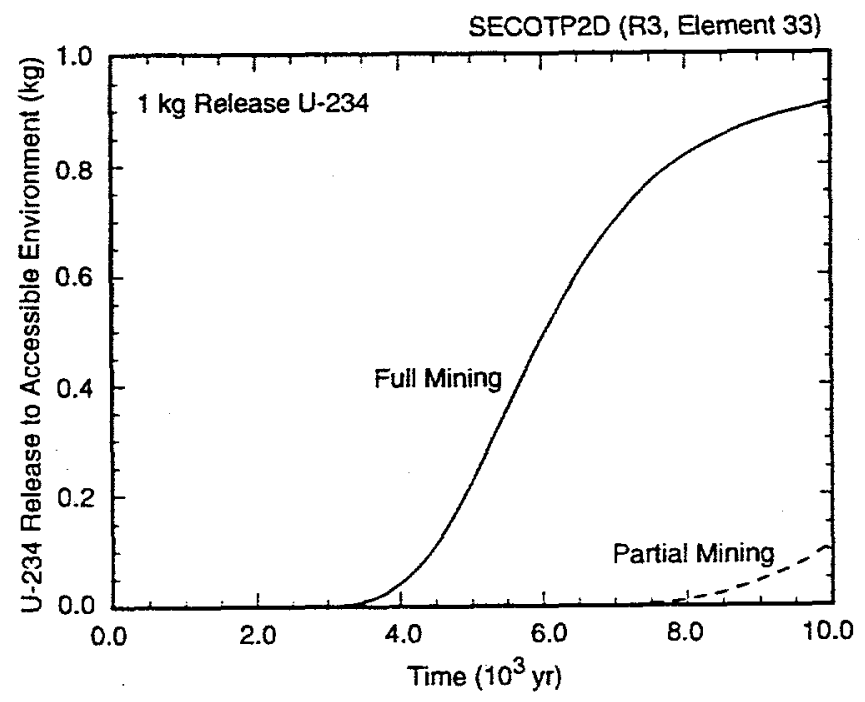

TR1-6342-5164-0

Fig. 13. Cumulative transport to accessible environment under partially mined and fully mined conditions for LHS element 33 of replicate $R 3$ for unit release $(1 \mathrm{~kg})$ of $U-234$ to the Culebra over the time interval $[0,50 \mathrm{yr}]$. 


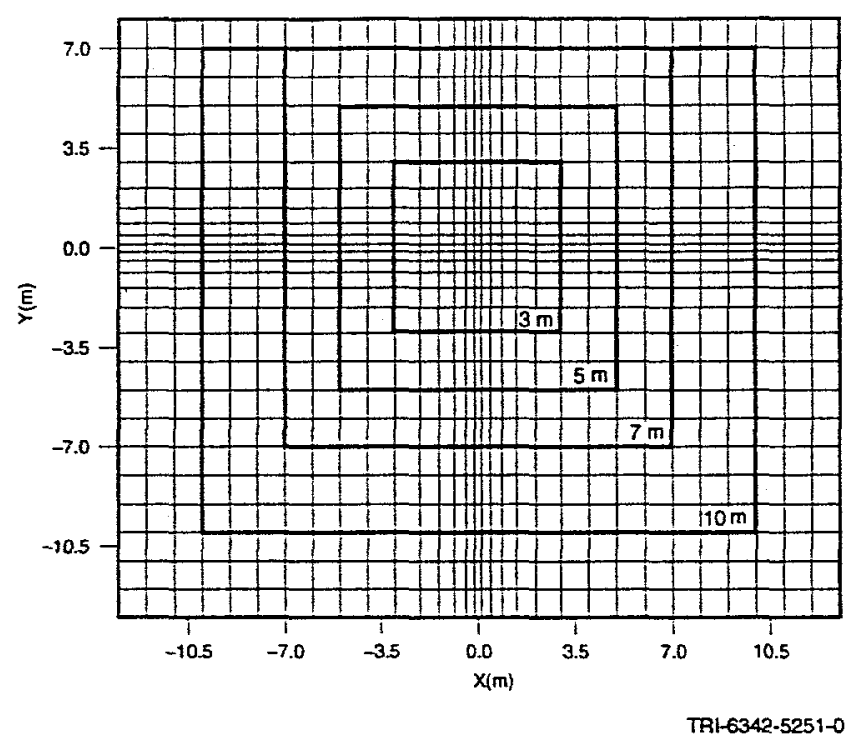

Fig. 14. Computational grid used in sensitivity analysis of SECOTP2D results. 

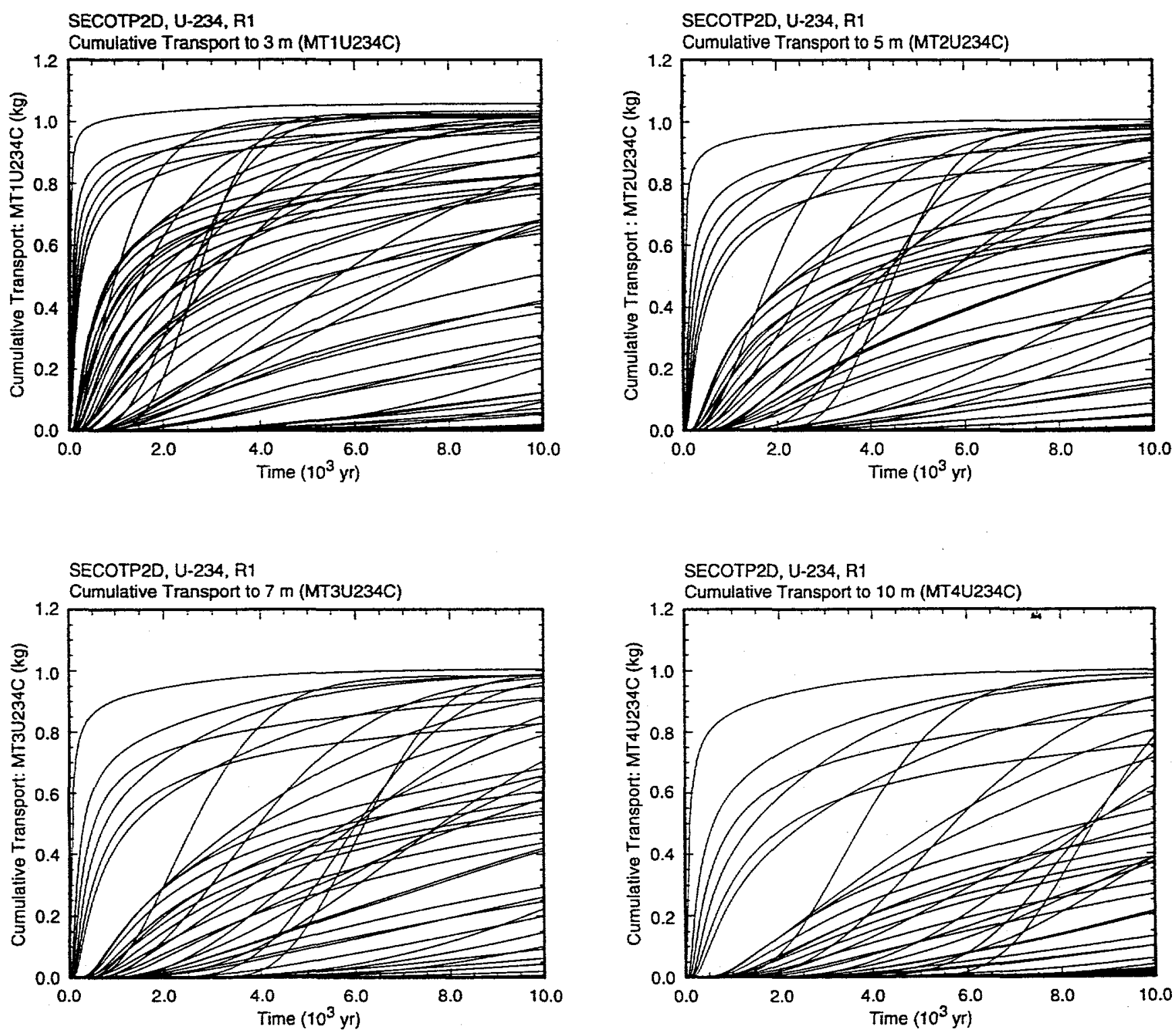

TRI-6342-5165-0

Fig. 15. Cumulative U-234 releases to the 3,5,7 and $10 \mathrm{~m}$ boundaries in Fig. 14 for $1 \mathrm{~kg}$ release over time interval $[0,50 \mathrm{yr}]$. 


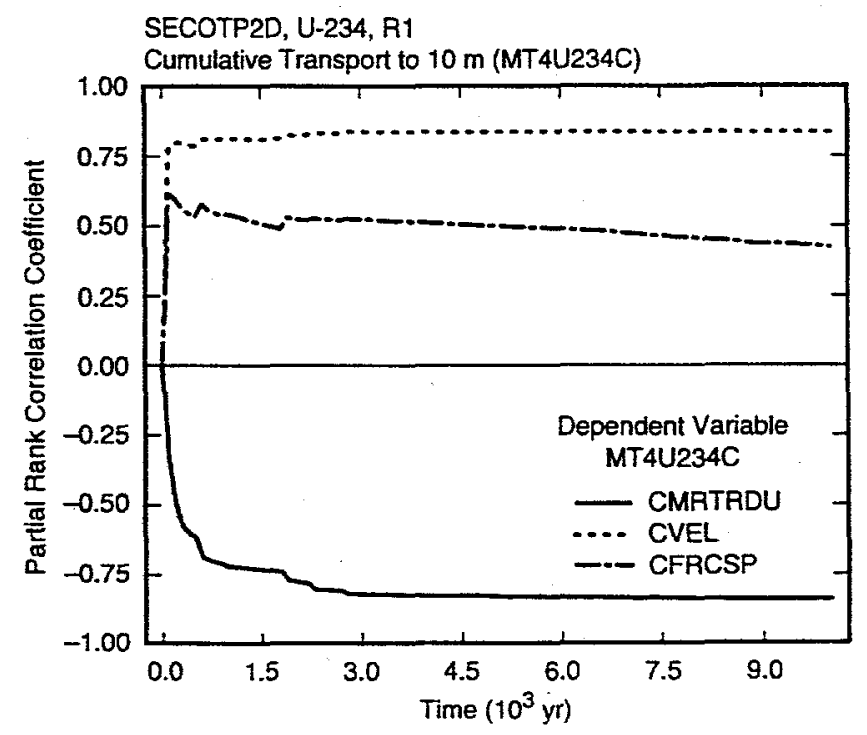

TRI-6342-5166-0

Fig. 16. Partial rank correlation coefficients (PRCCs) for cumulative U-234 releases across boundary $10 \mathrm{~m}$ from release point into Culebra Dolomite for $1 \mathrm{~kg}$ release over time interval $[0,50 \mathrm{yr}]$.

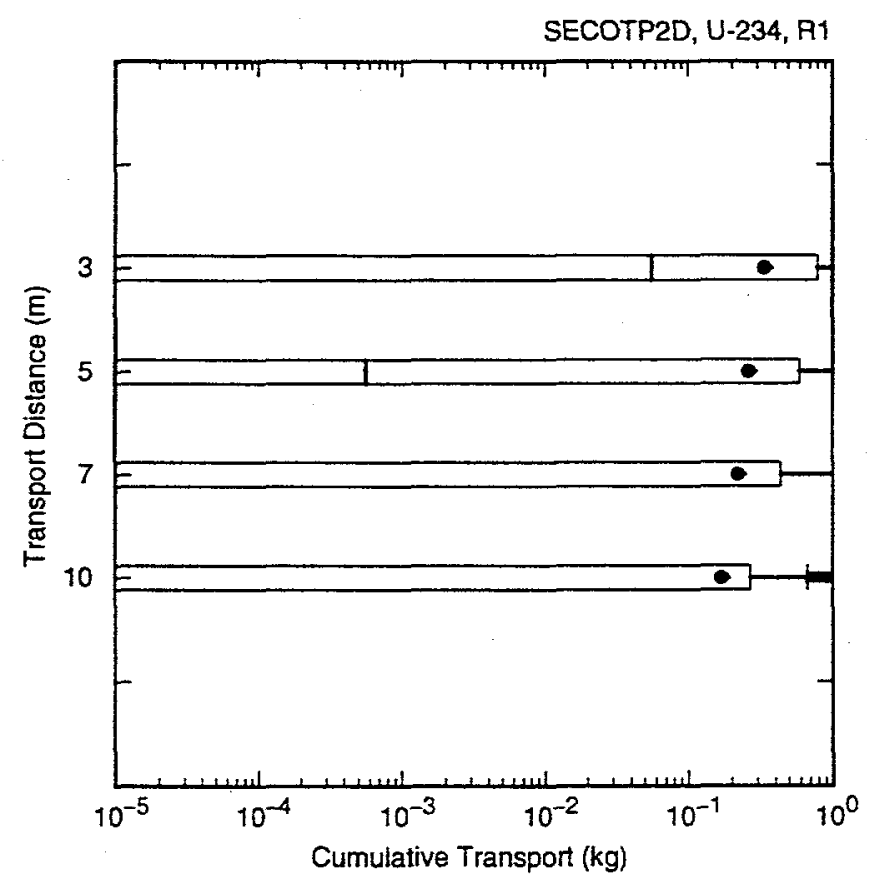

TRI-6342-5167-0

Fig. 17. Boxplot for cumulative transport over $10,000 \mathrm{yr}$ of U-234 across the 3,5, 7 and $10 \mathrm{~m}$ boundaries in Fig. 14 for a $1 \mathrm{~kg}$ release over the time interval [0,50 yr] (see Sect. 2, Ref. 16. for a discussion of boxplots). 

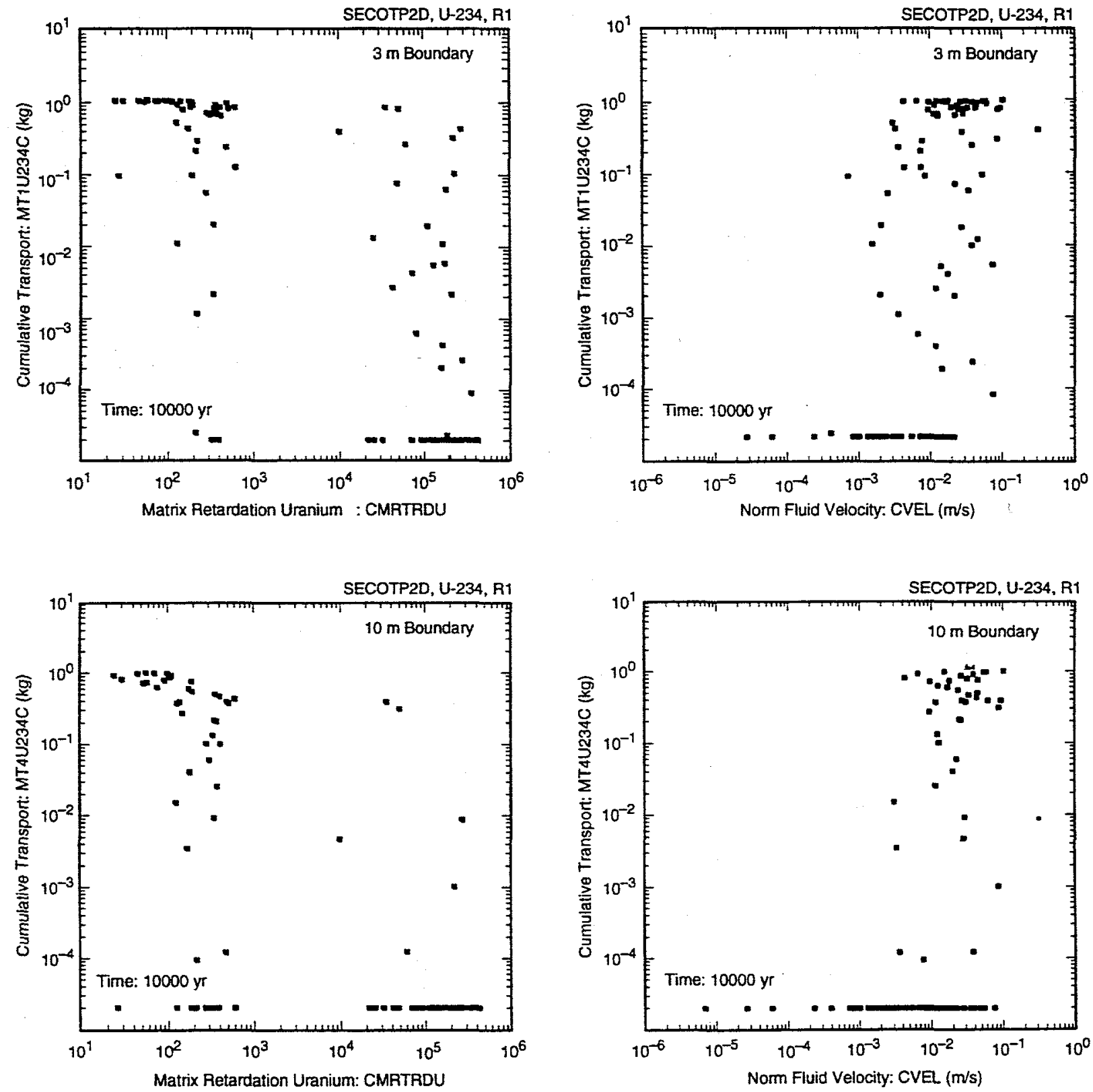

TRI-6342-5168-0

Fig. 18. Scatterplots for cumulative transport over 10,000 yr of U-234 across the 3 and $10 \mathrm{~m}$ boundaries in Fig. 14 for $1 \mathrm{~kg}$ release over time interval $[0,50 \mathrm{yr}]$ versus $C M R T R D U$ and $C V E L$. 
Table 1. Boundary Value Conditions Used for $h$ in Solution of Eq. (6) on Regional Model Domain Shown in Figs. 3 and 4

\section{No Flow Boundaries}

\begin{tabular}{|c|c|}
\hline$\partial h / \partial x=0$ & Dashed boundary on left and right in Fig. 4 \\
\hline$\partial h / \partial y=0$ & Dashed boundary on top in Fig. 4 \\
\hline & Constant Head Boundaries \\
\hline$h(x, y)$ & $\begin{array}{l}\text { Specified on solid boundary in Fig. 4; see Fig. } 6 \text { for example of specification on lower boundary } \\
\text { in Fig. } 4 .\end{array}$ \\
\hline
\end{tabular}

Table 2. Potential SECOTP2D Calculations for a Single LHS Element

\begin{tabular}{|c|l|}
\hline $\begin{array}{c}\text { SECOTP2D } \\
\text { Calculations }\end{array}$ & \\
\hline 1,2 & Description \\
3,4 & Dissolved Am-241 for partially and fully mined conditions \\
5,6 & Dissolved U-234, Th-230 for partially and fully mined conditions \\
7,8 & Dissolved Th-230 for partially and fully mined conditions \\
9,10 & Humic colloids for partially and fully mined conditions \\
11,12 & Microbial colloids for partially and fully mined conditions \\
13,14 & Mineral fragment colloids for partially and fully mined conditions \\
15,16 & Actinide intrinsic colloids for partially and fully mined conditions \\
\hline
\end{tabular}


Table 3. Results Available for Use in CCDF Construction for Radionuclide Releases Resulting from Groundwater Transport through the Culebra Dolomite

$\tau_{m}=$ times (yr) used to record results of unit release calculations with SECOTP2D for the Culebra, $m=1,2, \ldots, n T T+1=201$, with $\tau_{1}=0 \mathrm{yr}$ and $\Delta \tau_{m}=50 \mathrm{yr}$

$n T I=$ number of time intervals $\left[\tau_{m}, \tau_{m+1}\right], m=1,2, \ldots, n T I$, defined by $\tau_{m}, m=1,2, \ldots, n T I+1$

$u D P\left(j, k, l, \tau_{m}\right)=$ release $(\mathrm{kg})$ to accessible environment of element $l$ of decay chain $j$ resulting from a $1 \mathrm{~kg}$ dissolved release of element $k$ of decay chain $j$ to the Culebra over time interval $\left[\tau_{m}, \tau_{m+1}\right]$ and subsequent transport under partially mined conditions between $\tau_{m}$ and 10,000 yr. Source: SECOTP2D (see Table 6, Ref. 7).

$u D F\left(j, k, l, \tau_{m}\right)=$ release $(\mathrm{kg})$ to accessible environment of element $l$ of decay chain $j$ resulting from a $1 \mathrm{~kg}$ dissolved release of element $k$ of decay chain $j$ to the Culebra over time interval $\left[\tau_{m}, \tau_{m+1}\right]$ and subsequent transport under fully mined conditions between $\tau_{m}$ and 10,000 yr. Source: SECOTP2D (see Table 6, Ref. 7).

$u C P\left(s, \tau_{1}\right)=$ cumulative release $(\mathrm{kg})$ to accessible environment through time $\tau_{l}$ of colloid specie $s$ due to a $1 \mathrm{~kg}$ release of colloid specie $s$ to the Culebra over time interval $\left[\tau_{1}, \tau_{2}\right]$ and subsequent transport under partially mined conditions. Assumed to be 0 ; otherwise, would be calculated with SECOTP2D.

$u C F\left(s, \tau_{1}\right)=$ cumulative release $(\mathrm{kg})$ to accessible environment through time $\tau_{l}$ of colloid specie $s$ due to a $1 \mathrm{~kg}$ release of colloid specie $s$ to the Culebra over time interval $\left[\tau_{1}, \tau_{2}\right]$ and subsequent transport under fully mined conditions. Assumed to be 0 ; otherwise, would be calculated with SECOTP2D. 
Table 4. Calculation of Groundwater Transport Release $f_{S T}\left(\mathbf{x}_{S t}\right)$ through the Culebra Dolomite for an Arbitrary Future $\mathbf{x}_{s t}$ of form in Eq. (1) of Ref. 7

Notation:

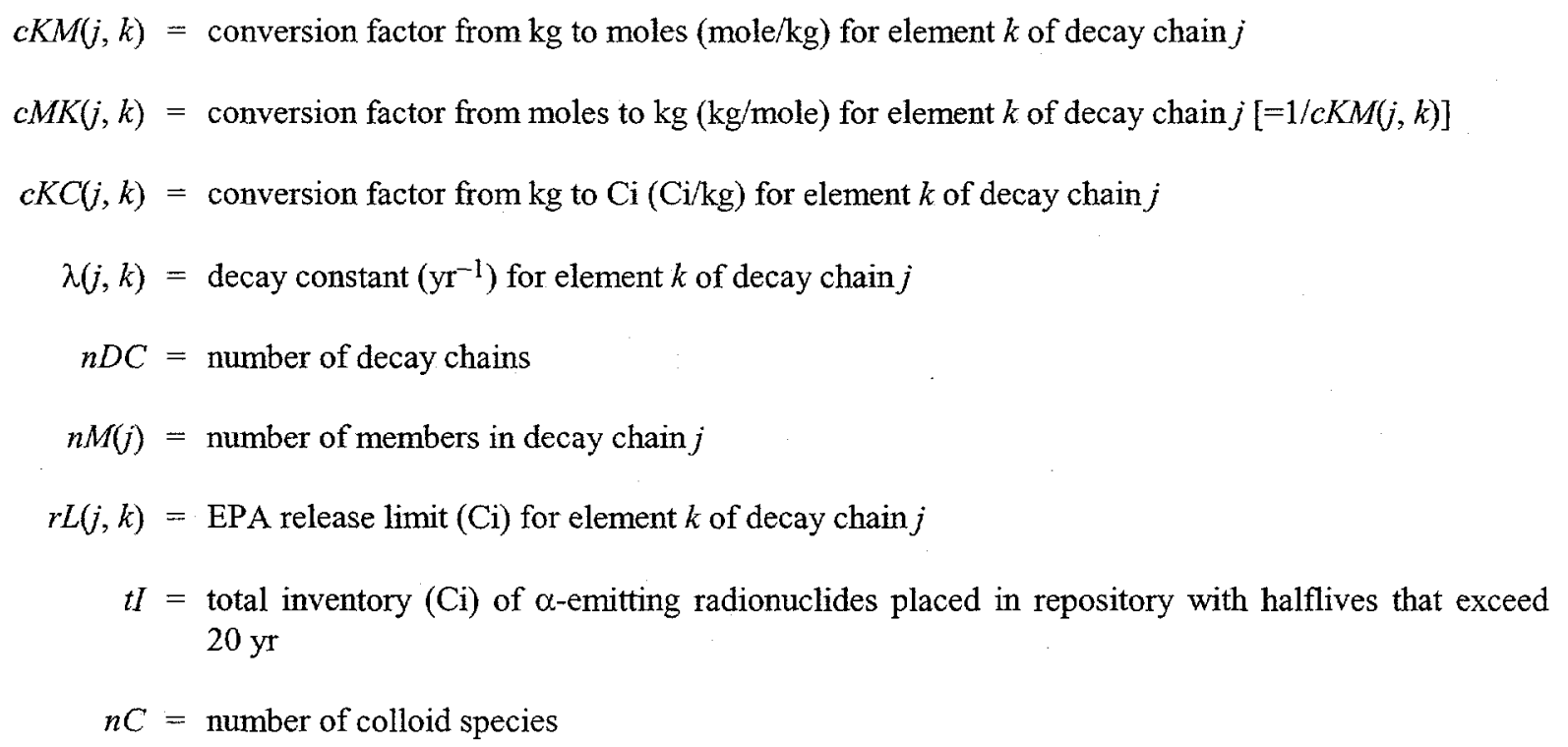

Dissolved release $r D(j, k)$ of element $k$ of decay chain $j$ :

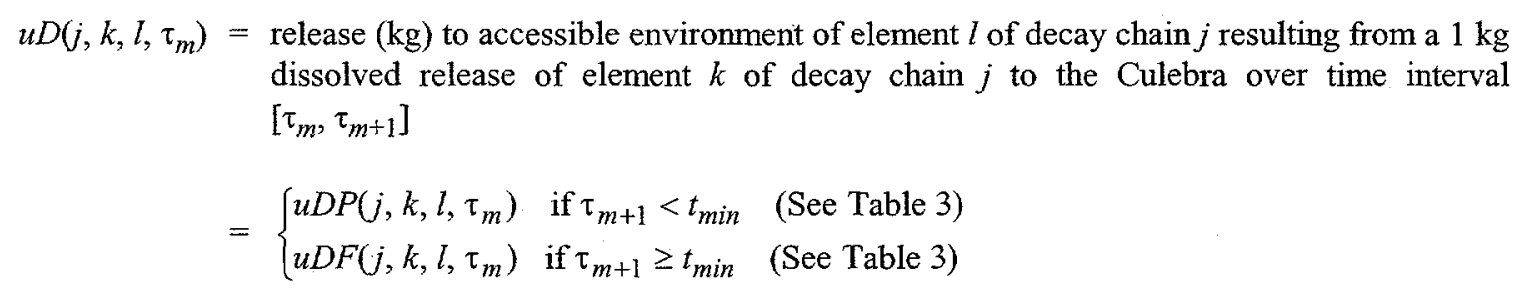
$d R D\left(j, k, \tau_{m}, \tau_{m+1}\right)=$ dissolved release $(\mathrm{kg})$ to Culebra of element $k$ of decay chain $j$ over time interval $\left[\tau_{m}, \tau_{m+1}\right]$
$=c R D\left(j, k ; \tau_{m+1}\right)-c R D\left(j, k, \tau_{m}\right)$ (see Table 8, Ref. 12)

$r D(j, k)=$ release $(\mathrm{kg})$ to accessible environment of element $k$ of decay chain $j$ resulting from dissolved releases into the Culebra

$=\sum_{m=1}^{n T I} \sum_{p=1}^{k} d R D\left(j, p, \tau_{m}, \tau_{m+1}\right) u D\left(j, p, k, \tau_{m}\right)$ 
Table 4. Calculation of Groundwater Transport Release $f_{S T}\left(\mathbf{x}_{s t}\right)$ through the Culebra Dolomite for an Arbitrary Future $\mathbf{x}_{s t}$ of form in Eq. (1) of Ref. 7 (continued)

Colloidal release $r C(j, k)$ of element $k$ of decay chain $j$ :

$u C\left(s, \tau_{1}, \tau_{m}\right)=$ release $(\mathrm{kg})$ to accessible environment of colloid specie $s$ over time interval $\left[\tau_{m}, \tau_{m+1}\right]$ resulting from a $1 \mathrm{~kg}$ release of colloid specie $s$ to the Culebra over time interval $\left[\tau_{l}, \tau_{l+1}\right]$

$$
=\left\{\begin{array}{lll}
u C P\left(s, \tau_{m+1-l}\right)-u C P\left(s, \tau_{m-l}\right) & \text { if } \tau_{m+1}<t_{\min } & \text { (See Table 3) } \\
u C F\left(s, \tau_{m+1-l}\right)-u C F\left(s, \tau_{m-l}\right) & \text { if } \tau_{m+1} \geq t_{m i n} & \text { (See Table 3) }
\end{array}\right.
$$

$d R C\left(s, j, k, \tau_{1}\right)=$ amount $(\mathrm{kg})$ of element $k$ of decay chain $j$ attached to colloid specie $s$ released to Culebra over time interval $\left[\tau_{l}, \tau_{l+1}\right]$

$$
=c R C\left(s, j, k, \tau_{l+1}\right)-c R C\left(s, j, k, \tau_{l}\right) \quad \text { (see Table 8, Ref. 12) }
$$

$a C\left(s, j, k, \tau_{1}, \tau_{m}\right)=$ amount $(\mathrm{kg})$ of element $k$ of decay chain $j$ attached to colloid specie $s$ over time interval $\left[\tau_{m}, \tau_{m+1}\right]$ due to releases over time interval $\left[\tau_{l}, \tau_{l+1}\right]$

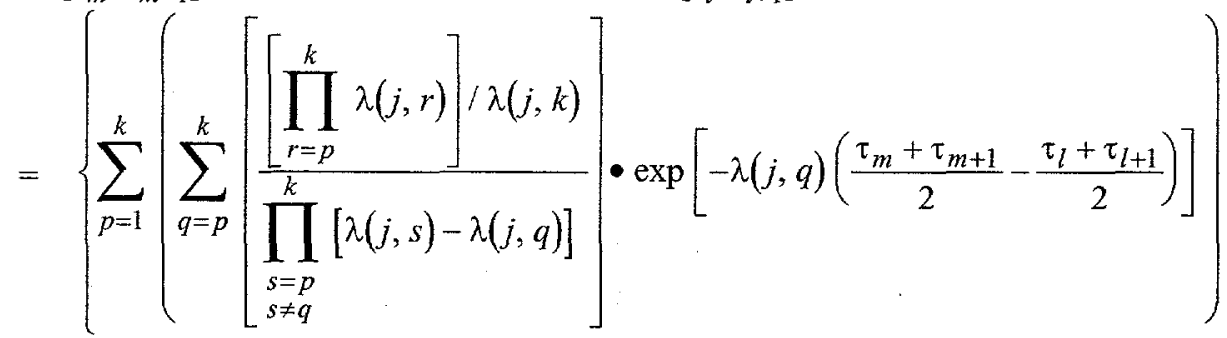

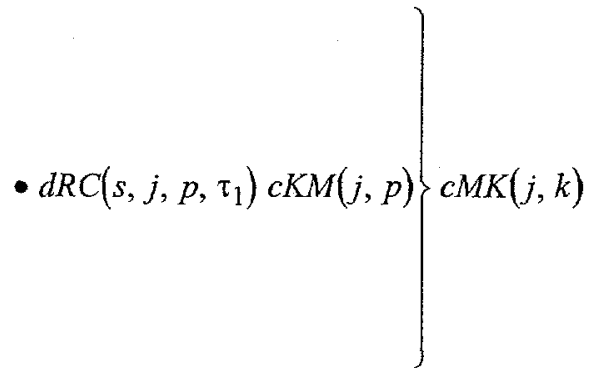

$r C I\left(s, j, k, \tau_{m}\right)=$ amount $(\mathrm{kg})$ of element $k$ of decay chain $j$ attached to colloid specie $s$ released to accessible environment over time interval $\left[\tau_{m}, \tau_{m+1}\right]$

$$
=\sum_{l=1}^{m} a C\left(s, j, k, \tau_{1}, \tau_{m}\right) u C\left(s, \tau_{1}, \tau_{m}\right)
$$

$r C(j, k)=$ release $(\mathrm{kg})$ to accessible environment of element $k$ of decay chain $j$ resulting from colloidal releases into the Culebra 
Table 4. Calculation of Groundwater Transport Release $f_{S T}\left(\mathbf{x}_{s t}\right)$ through the Culebra Dolomite for an Arbitrary Future $\mathbf{x}_{s t}$ of form in Eq. (1) of Ref. 7 (continued)

$$
=\sum_{s=1}^{n C} \sum_{m=1}^{n T I} r C l\left(s, j, k, \tau_{m}\right)
$$

Evaluation of $f_{S T}\left(\mathbf{x}_{s t}\right)$ :

$$
f_{S T}\left(\mathbf{x}_{s t}\right)=\sum_{j=1}^{n D C} \sum_{k=1}^{n M(j)}\left\{\frac{[r D(j, k)+r C(j, k)] c K C(j, k)}{r L(j, k)}\right\}\left\{\frac{10^{6} \mathrm{Ci}}{t I}\right\}
$$

Table 5. Independent Variables Considered for Potential Inclusion in Sensitivity Analysis of U-234

\begin{tabular}{|c|c|}
\hline Variable & Description \\
\hline CFRCSP & Culebra fracture spacing (m). Defined in Table 1 of Ref. 8 \\
\hline$C F R C \dot{P} O R$ & Culebra fracture porosity. Defined in Table 1 of Ref. 8 \\
\hline CMTRXPOR & Culebra matrix porosity. Defined in Table 1 of Ref. 8 \\
\hline CMRTRDU & $\begin{array}{l}\text { Culebra matrix retardation for uranium. Defined by CMRTRDU }=1+\left[2800 \mathrm{~kg} / \mathrm{m}^{3}\right. \\
\left.(1-C M T R X P O R) K_{d}(\text { WOXSTAT })\right] / C M T R X P O R \text { with } K_{d}(W O X S T A T)=C M K D U 4 \text { if } \\
\text { WOXSTAT }=0 \text { and } K_{d}(\text { WOXSTAT })=C M K D U 6 \text { if } W O X S T A T=1\end{array}$ \\
\hline$C V E L$ & $\begin{array}{l}\text { Norm of fluid velocity vector calculated by SECOFL2D under partially mined conditions at } \\
\text { release point into Culebra and used in SECOTP2D calculations }(\mathrm{m} / \mathrm{s}) \text {. }\end{array}$ \\
\hline$C V E L C F$ & $\begin{array}{l}\text { Norm of fluid velocity vector multiplied by climate scale factor }(\mathrm{m} / \mathrm{s}): C V E L C F=C V E L \\
\text { CULCLIM }\end{array}$ \\
\hline CVELSC & $\begin{array}{l}\text { Norm of scaled fluid velocity within fracture } \mathrm{s}(\mathrm{m} / \mathrm{s}): C V E L S C=C V E L C U L C L I M / \\
C F R C P O R\end{array}$ \\
\hline CULCLIM & Climate scale factor for Culebra flow field. Defined in Table 1 of Ref. 8 \\
\hline WOXSTAT & Pointer variable for elemental oxidation states. Defined in Table 1 of Ref. 8 \\
\hline
\end{tabular}
Transport in Culebra Dolomite 
Table 6. Stepwise Regression Analyses with Rank-Transformed Data and Independent Variables in Table 5 for Cumulative Transport of U-234 over 10,000 yr Across the 3, 5, 7 and $10 \mathrm{~m}$ Boundaries in Fig. 14 for a $1 \mathrm{~kg}$ Release over the Time Interval [0,50 yr]

\begin{tabular}{|c|l|c|c|c|c|c|c|c|c|c|c|c|}
\cline { 2 - 12 } \multicolumn{1}{c|}{} & \multicolumn{3}{c|}{$3 \mathrm{~m}$} & \multicolumn{4}{c|}{$5 \mathrm{~m}$} & \multicolumn{3}{c|}{$7 \mathrm{~m}$} & \multicolumn{3}{c|}{$10 \mathrm{~m}$} \\
\hline Step $^{\mathrm{a}}$ & Variable $^{\mathrm{b}}$ & SRRC & $R^{2 \mathrm{~d}}$ & Variable & SRRC & $R^{2}$ & Variable & SRRC & $R^{2}$ & Variable & SRRC & $R^{2}$ \\
\hline 1 & CMRTRDU & -0.44 & 0.51 & CMRTRDU & -0.41 & 0.50 & CMRTRDU & -0.40 & 0.48 & CMRTRDU & -0.41 & 0.41 \\
2 & CVEL & 0.58 & 0.86 & CVEL & 0.59 & 0.86 & CVEL & 0.58 & 0.84 & CVEL & 0.61 & 0.80 \\
3 & CFRCSP & 0.16 & 0.89 & CFRCSP & 0.19 & 0.89 & CFRCSP & 0.21 & 0.88 & CFRCSP & 0.20 & 0.84 \\
4 & WOXSTAT & 0.31 & 0.91 & WOXSTAT & 0.32 & 0.91 & WOXSTAT & 0.37 & 0.90 & WOXSTAT & 0.29 & 0.85 \\
\hline
\end{tabular}

${ }^{a}$ Steps in stepwise regression analysis.

${ }^{b}$ Variables listed in order of selection in regression analysis.

${ }^{c}$ Standardized rank regression coefficients in final regression model.

${ }^{d}$ Cumulative $R^{2}$ value with entry of each variable into regression model. 